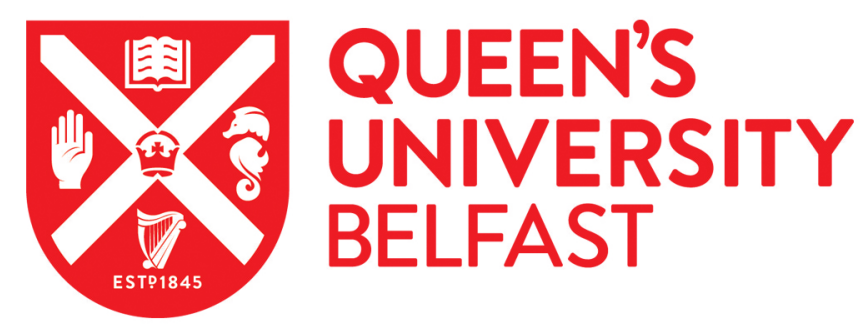

\title{
Microneedle arrays for vaccine delivery: the possibilities, challenges and use of nanoparticles as a combinatorial approach for enhanced vaccine immunogenicity
}

Rodgers, A. M., Cordeiro, A. S., Kissenpfennig, A., \& Donnelly, R. F. (2018). Microneedle arrays for vaccine delivery: the possibilities, challenges and use of nanoparticles as a combinatorial approach for enhanced vaccine immunogenicity. Expert Opinion on Drug Delivery, 15(9), 851-867.

https://doi.org/10.1080/17425247.2018.1505860

Published in:

Expert Opinion on Drug Delivery

Document Version:

Peer reviewed version

Queen's University Belfast - Research Portal:

Link to publication record in Queen's University Belfast Research Portal

Publisher rights

(C) 2018 Informa UK Limited trading as Taylor and Francis.

This work is made available online in accordance with the publisher's policies. Please refer to any applicable terms of use of the publisher.

\section{General rights}

Copyright for the publications made accessible via the Queen's University Belfast Research Portal is retained by the author(s) and / or other copyright owners and it is a condition of accessing these publications that users recognise and abide by the legal requirements associated with these rights.

Take down policy

The Research Portal is Queen's institutional repository that provides access to Queen's research output. Every effort has been made to ensure that content in the Research Portal does not infringe any person's rights, or applicable UK laws. If you discover content in the

Research Portal that you believe breaches copyright or violates any law, please contact openaccess@qub.ac.uk. 


\section{Microneedle arrays for vaccine delivery: The possibilities, challenges and use of nanoparticles as a combinatorial approach for enhanced vaccine immunogenicity}

Aoife Maria Rodgers ${ }^{1}$, Ana Sara Cordeiro ${ }^{1}$, Adrien Kissenpfennig ${ }^{2}$, Ryan F Donnelly ${ }^{1 *}$

${ }^{1}$ School of Pharmacy, Medical Biology Centre, Queens University Belfast, 97 Lisburn Road, Belfast BT9 7BL, United Kingdom.

${ }^{2}$ Centre for Experimental Medicine, School of Medicine, Dentistry \& Biomedical Science, Queens University Belfast, United Kingdom.

Aoife Maria Rodgers (Postdoctoral Research Fellow), School of Pharmacy, Medical Biology Centre, Queens University Belfast, 97 Lisburn Road, Belfast BT9 7BL, United Kingdom. Tel: +44 (0)28 9097 2333; fax: +44 2890247 794. E-mail: arodgers11@qub.ac.uk

Ana Sara Cordeiro (Postdoctoral Research Fellow), School of Pharmacy, Medical Biology Centre, Queens University Belfast, 97 Lisburn Road, Belfast BT9 7BL, United Kingdom. Tel: +44 (0)28 9097 2333; fax: +44 2890247 794. E-mail: a.cordeiro@qub.ac.uk

Adrien Kissenpfennig, (Deputy Director), Centre for Experimental Medicine, School of Medicine, Dentistry \& Biomedical Science, Queens University Belfast, United Kingdom. Tel: +44 (0)289097 6023. E-mail: a.kissenpfennig@qub .ac.uk

*Corresponding author at: Chair in Pharmaceutical Technology, School of Pharmacy, Queens University Belfast, Medical Biology Centre, 97 Lisburn Road, Belfast BT9 7BL, United Kingdom. Tel.: +44 $2890 \quad 972$ 251; fax: +44 $2890 \quad 247$ 794. E-mail address: r.donnelly@qub.ac.uk (R.F. Donnelly). 


\section{Table of Contents}

Abbreviations

Abstract

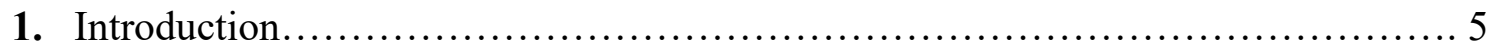

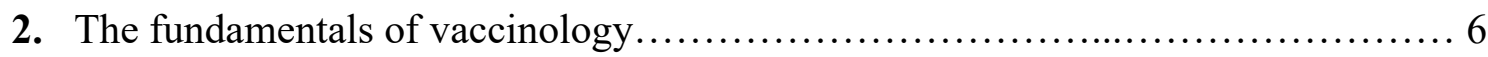

2.1 Disadvantages associated with current vaccination strategies: from logistical challenges to immunogenicity demands..................................... 9

3. Particulate vaccines for improved immunogenicity........................... 11

3.1 Polymeric NP for vaccination........................................ 12

4. The skin: a potential solution............................................. 15

4.1 Fundamental aspects of skin architecture and structure................... 15

4.2 Role of the skin in vaccination: an immunological perspective................ 17

5. Microneedle arrays circumvent skin barrier functions and facilitate

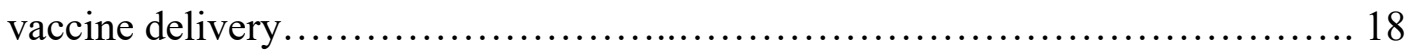

5.1 MN for vaccination - development and recent applications................. 21

6. MN-mediated delivery of particulate vaccines: a combinatorial approach for improved

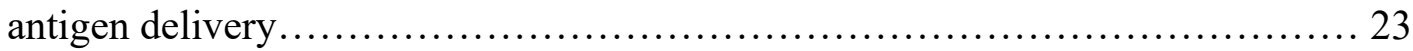

6.1 Dissolving MN-mediated NP vaccination............................... 24

6.1.1 Considerations in the manufacturing of dissolving $\mathrm{MN}$ for

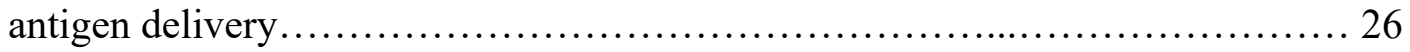

6.2 Solid and coated MN-mediated NP vaccination........................... 27

6.3 Hollow MN-mediated NP vaccination................................... 29

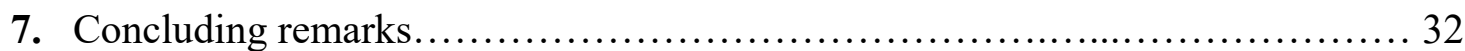

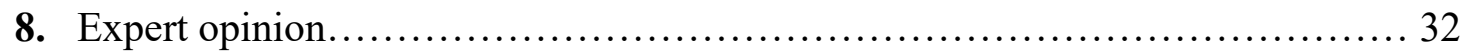

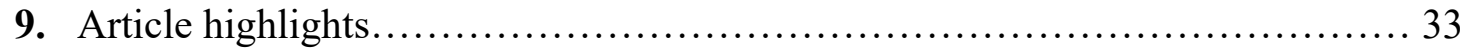




\section{Abbreviations}

APC

Alum

BMDC

CTL

CLR(s)

DC

GNP

$\operatorname{IFN} \gamma$

$\operatorname{IgG}$

IL

IM

$\mathrm{LN}$

$\mathrm{NP}(\mathrm{s})$

NOD

MHC

MSNP

$\mathrm{MN}(\mathrm{s})$

OCT

PAMP
Antigen presenting cell

Aluminium hydroxide

Bone marrow derived dendritic cells

Cytotoxic T lymphocyte

C-type lectin receptor(s)

Dendritic cell

Gelatin NP

Interferon gamma

Immunoglobulin

Interleukin

Intramuscular

Lymph node

Nanoparticle(s)

Nucleotide-binding oligomerization domain

Major histocompatibility complex

Mesoporous silica NP

Microneedle(s)

Optical coherence tomography

Pathogen-associated molecular pattern 
Poly(ethyleneimine)

PLA Poly(lactic acid)

PLGA Poly(lactic-co-glycolic acid)

PRR(s) Pattern recognition receptor(s)

PVP Poly(vinylpyrrolidone)

SEM Scanning electron microscope

$S C$

Stratum corneum

TCR

$\mathrm{T}$ cell receptor

TEM

Transmission electron microscope

TLR

Toll-like receptor

$\mathrm{TNF} \alpha$

Tumour necrosis factor alpha 


\section{ABSTRACT}

INTRODUCTION: Vaccination is undoubtedly one of the greatest breakthroughs of modern preventative medicine. Despite this, there remain problems surrounding delivery, efficacy and compliance. Thus, there is a pressing need to develop cost-effective vaccine delivery systems that could expand the use of vaccines, particularly within developing countries. Microneedle (MN) arrays, due to their ease of use, painlessness and ability to target skin antigen presenting cells, provide an attractive technological platform for improved vaccine delivery and efficacy. Studies have demonstrated enhanced immunogenicity with the use of $\mathrm{MN}$ in comparison to that of the conventional needle. More recently, dissolving MN have been used for efficient delivery of nanoparticles (NP), as a means to enhance antigen immunogenicity.

AREAS COVERED: This review introduces the fields of MN technology and nanotechnology and highlights the recent advances which have been made combining these two technologies for enhanced vaccine delivery and efficacy. Some of the key questions that remain to be addressed for adoption of $\mathrm{MN}$ in a clinical setting are also evaluated.

EXPERT OPINION: MN-mediated vaccine delivery holds potential for expanding access to vaccines, with individuals in developing countries likely to be the principal beneficiaries. The combinatorial approach of utilising MN coupled with NP, provides the opportunity to enhance the immunogenicity of vaccine antigens.

\section{KEYWORDS}

Antigen, microneedle (MN), nanoparticle (NP), skin, vaccine 


\section{INTRODUCTION}

The invention of vaccination is one of the greatest triumphs of modern preventative medicine. A vaccine may be defined as a biological preparation that is used to establish or improve immunity to a particular disease. Vaccine administration stimulates specific immune responses and induces long-lasting immunological memory to protect upon subsequent encounter with a pathogenic organism. As such, it is the most effective means of controlling the spread of infectious disease and preventing disease-related morbidity and mortality. The elimination of smallpox and estimated avoidance of 2.5 million deaths per year from diphtheria, tetanus, whooping cough and measles through vaccinations, exemplify their importance for global health [1].

For successful vaccination, appropriate administration is key. At present, most vaccines are administered intramuscularly or subcutaneously via needle and syringe with associated disadvantages including pain, needle phobia, poor patient compliance and risk of needle-stick injuries [2]. Additionally, many current vaccines must be maintained within specific temperature ranges to retain their potency. This is referred to as the 'cold chain', and is particularly difficult to maintain in developing countries, due to limited infrastructure, often resulting in vaccine wastage [3]. Thus, significant barriers for effective vaccine distribution and administration remain as challenges in this field.

In recent years, the use of nanoparticle (NP)-based vaccines has emerged as a novel approach to enhance antigen immunogenicity. NPs (1-1000 nm) have been used as antigen carriers, allowing controlled and prolonged antigen delivery at the vaccination site, while protecting antigen from degradation. Moreover, NP have been shown to elicit their own inherent immunostimulatory properties and have effects comparable to those of traditional vaccine adjuvants such as aluminium hydroxide (alum) [4]. Finally, these advanced antigen carriers 
showed promising results in eliciting immune responses through non-parenteral routes of administration and as needle-free immunization approaches [5].

In the search for alternative administration routes for vaccines, microneedle (MN) arrays have been proposed to improve vaccine coverage and efficacy [6]. $\mathrm{MN}$ are minimally invasive devices that consist of a series of micron-sized needles attached to a base support. The needles are typically less than $1 \mathrm{~mm}$ long and do not irritate pain receptors localised in deeper skin regions. MN have garnered considerable interest for delivery of vaccines and other actives to the epidermal and dermal skin layers. In contrast to the subcutaneous fat and muscle tissue which contain relatively few antigen-presenting cells (APC), namely dendritic cells (DCs), the skin contains a complex DC network [5]. Delivering vaccines directly into the skin places antigen in close proximity with skin APCs, often resulting in lower doses of antigen being required and superior immunological responses than that with other routes of delivery [7].

The use of MN for the delivery of antigen-loaded NP has emerged as a novel outstanding combinatorial approach to capitalise on the advantages of both systems for enhanced vaccine efficacy. Accordingly, this review aims to provide an updated overview of the combination of NP and MN for vaccine delivery. Herein, we provide an introduction into the mechanisms and challenges of vaccination, the emerging nanoparticle-based adjuvants and the fundamental aspects of vaccine delivery to the skin. Following this, we focus on the potential of MN as novel vaccine delivery devices, particularly in combination with NP. Finally, some of the challenges that need to be addressed if $\mathrm{MN}$ are to be adopted in the clinical setting are evaluated.

\section{THE FUNDAMENTALS OF VACCINOLOGY}

The process of vaccination involves exposing the immune system to an antigen in order to generate immunological memory. The immune system comprises a network of cells, tissues 
and lymphoid organs, which orchestrate host defence, allowing the elimination or neutralisation of pathogens and foreign substances via constant immune surveillance. A complex and sophisticated arsenal of weapons awaits evading pathogens, acting through two complementary arms, termed innate and adaptive immunity [4].

During the early phase of the immune response, APCs capture pathogens by phagocytosis. Dendritic cells, regarded as the most potent APCs, are present as sentinels in the periphery where they sample the environment for foreign antigens. Upon encounter of antigenic material, DCs undergo a process referred to as maturation whereby they lose the capacity to uptake further antigen and acquire the ability to present the antigen to naïve $\mathrm{T}$ cells in the context of major histocompatibility complex (MHC) class I or II. Maturation is accompanied by changes in the expression pattern of chemokine receptors, upregulation of co-stimulatory molecules (CD80, CD86) and $\mathrm{T}$ cell adhesion molecules (CD58 and CD48), and cytokines including interleukin (IL)-12. DC 'homing' to the LN also occurs, as it is here where DCs encounter and activate $\mathrm{T}$ cells $[8]$.

Following ingestion by DC, the antigen is degraded in endosomes or phagosomes, resulting in antigenic peptides for presentation on MHC I or MHC II molecules to naïve $\mathrm{T}$ cells. Exogenous/extracellular antigens are generally loaded onto MHC II molecules, whereas endogenous/intracellular antigens are typically presented on MHC I molecules. Moreover, exogenous/extracellular antigens may also be loaded onto MHC class I molecules for induction of a peptide restricted $\mathrm{CD}^{+} \mathrm{T}$ cell response (cytotoxic $\mathrm{T}$-cell response $-\mathrm{CTL}$ ) in a process referred to as antigen cross-presenting. This process is unique to DCs and macrophages and offers an attractive pathway to elicit CTL response. After loading of antigen fragments onto MHC I or II molecules, the peptide/MHC complex is transported to the cell surface for interaction with naïve T cells. Upon encounter of a DC with a T cell, the antigen-MHC complex 
is recognised by $\mathrm{T}$ cell receptors (TCR). Concurrently, a second co-stimulatory signal is required in order for the $\mathrm{T}$ cell to undergo clonal expansion and differentiation into effector and memory cells. The absence of such signals induces T cell anergy or tolerance [9].

The adaptive response is mediated by lymphocytes ( $\mathrm{T}$ and $\mathrm{B}$ cells) and may be divided into humoral (antibody) or cell-mediated (cytotoxic $\mathrm{T}$ cell) responses. Upon activation, $\mathrm{CD}^{+} \mathrm{T}$ cells differentiate into distinct sub-populations, for example Th1 or Th2 cells, to drive an appropriate response against the perceived threat [10]. This differentiation is dependent upon a complex network of cytokine signalling and transcription factors. For instance, Th1 cells produce interferon (IFN)- $\gamma$ and IL-2, whereas Th2 cells secrete IL-4 and IL-10. Activated $\mathrm{CD}^{+}$cells become cytotoxic $\mathrm{T}$ cells which can kill cells directly or through the release of cytotoxins and produce cytokines such as IFN- $\gamma$ and TNF- $\alpha$. In addition to the classical Th1 and Th2 cells, other important $\mathrm{CD}^{+} \mathrm{T}$ cells include Th17 cells which play an important role in host defence against extracellular bacteria, particularly on mucosal surfaces [11], and regulatory $\mathrm{T}$ cells which are involved in the maintenance of immunological self-tolerance and immune homeostasis. B cells can recognise antigenic peptide-MHC class II complexes and are co-stimulated by $\mathrm{CD}^{+} \mathrm{T}$ cells or cytokines to undergo clonal expansion and differentiation becoming antibody-secreting plasma cells [8].

Considering the complex nature of the immune system, it is established that the vaccine characteristics influence the type and magnitude of immune response elicited. Several types of vaccines have been used to date, including live attenuated, killed or inactivated, toxoid and subunit vaccines. Moreover, a number of more complex, innovative vaccines such as DNA vaccines are under development [12]. Regardless of the type of vaccine, they all function by mirroring a disease-causing pathogen, stimulating the immune system to recognise it as foreign and causing humoral or cellular immunity against it. Upon further encounter with the same 
pathogen, the immune system can more readily challenge it, thereby diminishing the devastating effects of disease that would otherwise occur [13].

\subsection{Disadvantages associated with current vaccination strategies: From logistical challenges to immunogenicity demands}

Despite the effectiveness of vaccination in global healthcare, there remain a number of disadvantages and challenges surrounding current vaccination approaches. With few exceptions, vaccines are administered by hypodermic needle and syringe into the intramuscular or subcutaneous space, requiring trained healthcare workers for correct vaccine reconstitution and administration. The primary risk associated with this approach is the transmission of diseases among patients, healthcare providers and the community. This is particularly important within developing countries where correct disposal of needles is difficult to implement and reuse of contaminated needles is common practice [14]. Vaccination via the traditional hypodermic needle is also associated with pain, suffering and distress, often leading to poor patient compliance. Needle phobia is common in both adults and children and a vast number of studies have documented vaccination non-compliance because of this $[15,16]$.

As previously mentioned, due to temperature sensitivity, the majority of currently available vaccines require storage at specific temperature ranges, most often $2-8^{\circ} \mathrm{C}$, from their manufacture through to distribution and reconstitution. Cold chain is a term used to refer to the materials, equipment and procedures that are necessary to maintain vaccines within this temperature range. Maintaining the cold chain during transport, storage, and handling is associated with substantial costs and represents a significant burden in low resource environments, often with limited infrastructure [3]. Stabilisation of vaccines or alternative methods of vaccine delivery that do not require cold chain storage could significantly reduce 
vaccination costs, limiting vaccine wastage and offering simplified storage, distribution and disposal [17].

In addition to the logistical and safety concerns, there is also a requirement for increased vaccine effectiveness from an immunological perspective. Most effective traditional vaccines are based on live-attenuated variants of the targeted pathogen. Such vaccines do not require adjuvants because they comprise bacterial or viral compounds that activate the innate immune system to enhance immunity [8]. Administration of these vaccines induces asymptomatic infections and generates long-lived memory, similar to what would be achieved in an individual following natural infection. Despite the impressive success of these vaccines, their potential toxicity and reactogenicity have led to the search for optimised antigens [18]. While the use of inactivated pathogens, synthetic peptides and recombinant protein subunits is advantageous in terms of safety and cost-effectiveness, these often exhibit poorer immunogenicity [19]. Thus, the co-delivery of adjuvants is pivotal to facilitate the induction of robust protective immunity [20]. Adjuvants can function like a pathogen-associated molecular pattern (PAMP), triggering innate immune responses through different mechanisms. This in turn, results in the activation and maturation of APCs and initiation of adaptive immune response [21].

Alum, a particulate formulation of aluminium salts, is the most widely used adjuvant for nonliving vaccines and was the only licenced adjuvant for human use until 2009 [22]. It is a component of many human vaccines, including diphtheria, tetanus and meningococcal, to name a few. Despite being effective at eliciting antibody responses against a number of pathogens, alum is a poor inducer of cell-mediated immunity. Specifically, it has been shown to activate immunosuppressive mechanisms following vaccination which limit its capacity to induce Th1 responses [23]. However, the induction of strong cellular immune responses, including cytotoxic T cells, Th1 and Th17 responses is required for the prevention of difficult to treat 
infections including those by intracellular pathogens including Klebsiella pneumoniae and extracellular pathogens such as Streptococcus pneumoniae [8]. Accordingly, there remains a requirement for the development of innovative adjuvants and delivery systems that enhance cell-mediated immunity as we move towards the era of modern vaccines. In this regard, NPs have received particular attention.

Therefore, despite the significant success of numerous vaccines and the role they have played and continue to play in public health, many challenges remain. Accordingly, the development of innovative vaccines against challenging pathogens and of effective adjuvants to potentiate an adequate immune response are among the most important vaccine research goals. Furthermore, the development of vaccine formulations and delivery strategies that circumvent the necessity for cold chain storage and the use of hypodermic needles could prevent the perpetual problems of vaccine wastage and disease transmission through unsafe injection practices.

\section{PARTICULATE VACCINES FOR IMPROVED IMMUNOGENICITY}

Nanotechnology offers the prospect of fabricating NP of differing composition, size, shape and surface properties, all of which can be tailored to achieve the desired immune response [24]. The use of NP for administration of vaccines has received tremendous interest due to their numerous advantageous features [25]. The formulation of antigens in NP can be achieved through different approaches. Antigens may be encapsulated within NP, which protect them from degradation, providing their sustained release and improving their uptake by APC [7]. NPs are also capable of mimicking pathogens, thus increasing the possibilities of an effective immune response [25]. Moreover, NPs offer the possibility of facilitating antigen uptake by DC through coupling of a DC receptor ligand to the NP, as reviewed elsewhere [26]. While 
several examples of NP are being developed (Figure 1), this review focuses specifically on the use of polymeric NP for vaccine delivery.
A. Gold NP
B. Polymeric NP
C. Dendrimer
D. Liposome
E. Carbon nanotube
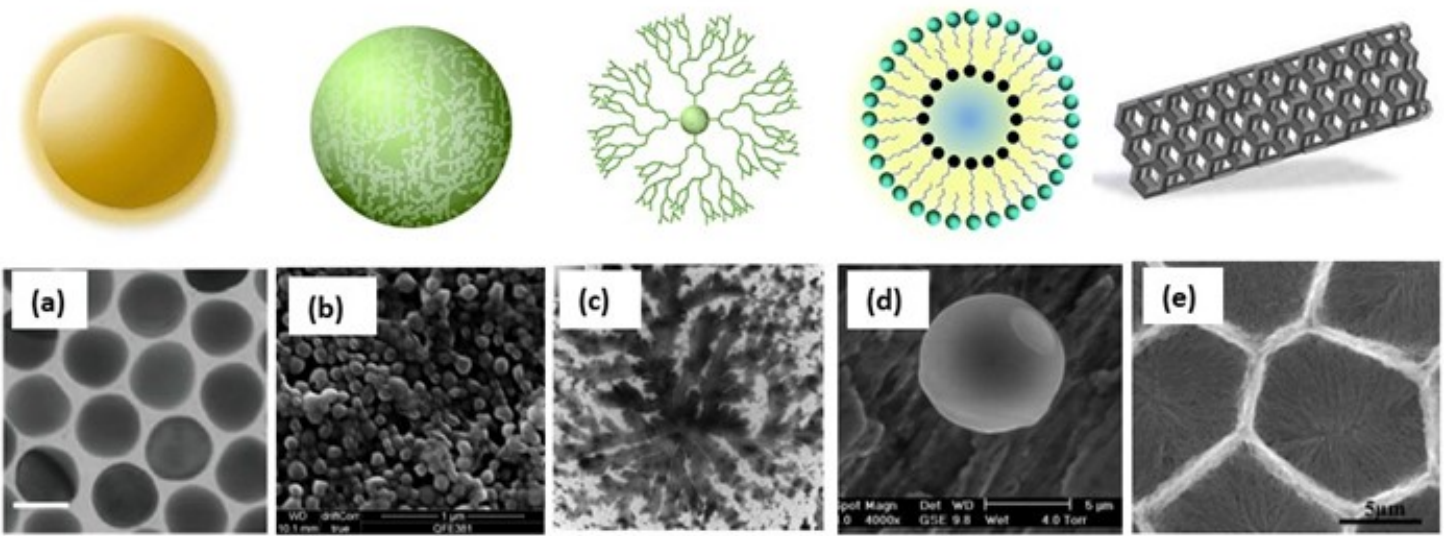

Figure 1. A diagrammatic representation of various types of NPs with potential interest as antigen carriers within microneedle platforms: (A) Gold NP, and (a) representative TEM image of a spherical gold NP, scale bar $40 \mathrm{~nm}$. (B) A polymeric NP and (b) representative SEM image of PLGA NP, scale bar $1 \mu \mathrm{m}$. (C) Dendrimer and (c) representative TEM image of dendrimer, direct Mag 6000X. (D) Liposome and (d) representative SEM image of a liposome, scale bar $5 \mu \mathrm{m}$. (E) Carbon nanotube and (e) representative SEM image of a typical honeycomb-like pattern, hexagon honeycomb was composed of carbon nanotubes, scale bar $5 \mu \mathrm{m}$. Nonexhaustive list. Reproduced with permission from [28-31], (b)- unpublished data.

\subsection{Polymeric NPs for vaccine delivery}

Biodegradable polymer-based NPs $(1-1000 \mathrm{~nm})$ have gained tremendous interest in vaccine delivery applications. These particles are prepared from aqueous polymer blends that assemble in nano-sized structures in appropriate conditions, either by electrostatic or hydrophobic interactions. Both synthetic and natural biodegradable polymers have been used for NP 
formulations. Examples of synthetic polymers include poly(lactic-co-glycolic-acid) PLGA, poly lactic acid (PLA) and polycaprolactone [31], and examples of naturally occurring polymers include polysaccharides such as chitosan and dextran [18].

For NPs to successfully deliver antigen to APC, they first need to access the tissues where these cells are present. Following parenteral administration, depending on the physicochemical properties of the NPs, they may directly drain to the closest LN, or reside at the administration site whereby they attract APC, in particular DC. As demonstrated by Manolova et al., small NPs $(<200 \mathrm{~nm})$ can freely drain to the LN where they are taken up by resident DC, whereas large NP depend on cellular transport from DC migrating from the skin [32]. It is widely reported that the encapsulation of antigens within NPs facilitates their uptake by APCs and may induce enhanced immune responses in comparison with soluble antigen [33]. Importantly, the internalisation of particulate vaccines via phagocytosis into phagosomes is important for antigen cross-presentation. Thus, particulate vaccines are an attractive option for the induction of cellular immune responses, in contrast to soluble antigen which is normally presented by MHC class II pathway and poorly cross-presented [8].

Among different NP properties, size, shape and surface characteristics may all play an important role in the uptake of NPs by APC. The two major types of APCs capable of antigen uptake and processing are DCs and macrophages. However, despite their similar functions, only DCs have the capacity to migrate from tissue to the LNs to prime naïve T cells. Thus, for vaccine delivery to DC, it is important to encapsulate antigen within NPs that are preferentially taken up by DCs. Studies have demonstrated that DCs predominantly internalise NPs with a size between 20 and $200 \mathrm{~nm}$, while larger NPs from 0.5 to $5 \mu \mathrm{m}$ are preferentially taken up by macrophages $[34,35]$. The site through which NPs are administered also influences their uptake. Newman and colleagues showed that intradermal administration of PLGA NPs resulted 
in their uptake by DCs, whereas intraperitoneal delivery resulted in uptake by macrophages [36].

Among other parameters influencing NPs uptake and immunogenicity are shape and surface charge. The influence of such parameters has been reviewed elsewhere [31]. In short, NPs that are non-spherical in shape have been shown to have improved membrane attachment, but are not efficiently taken up by APC [37]. NP surface charge is important for endocytosis mechanisms. Cell membranes are negatively charged, thus, NPs that are cationic can be more efficiently taken up by APC than that of anionic NPs. NPs can be taken up by cells through differing pathways, depending on their properties. A number of reviews have described the mechanisms through which NP are internalised and the effects of NP properties in this process. In brief, phagocytosis and pinocytosis (including clathrin-mediated endocytosis, caveolaemediated endocytosis and macropinocytosis) are the two main endocytic pathways used for uptake of NPs [31].

Following antigen uptake by APC (importantly DC), the antigen is processed and the antigenic fragment is presented on the surface of these cells through MHC molecules. Depending on the endocytosis pathways, which is influenced by NP properties and the antigen delivered, two types of immune response pathways can be potentially activated (MHC-I or MHC-II), as previously described in this review. The uptake of NPs can also be further enhanced by surface modification of the NPs with DC-binding ligands such as monoclonal antibodies, targeting DEC-205 (C type lectin receptor), DC40 (TNF- $\alpha$ family receptor), or CD11c (integrin receptor) [38].

Aside from their functions as antigen carriers, NPs have also been evaluated for their immunostimulatory properties, acting as adjuvants per se. A study by Tamayo and co-workers showed that poly(anhydride) nanoparticles could act as active Th1 adjuvants through TLR-2, - 
4 and -5 exploitation [39]. Importantly, it has been reported that NP could induce the activation of an intracellular stress-sensing pathway known as the inflammasome [40]. As previously highlighted, pattern recognition receptors (PRRs) recognise PAMPs, such as cell wall components of bacteria, viral DNA and CpG DNA, which naturally target these receptors. Therefore, stimulation of PRRs has been used in vaccination for many years. These receptors recognise the presence of infection, initiating innate immune responses, but also play a direct role on the induction of adaptive immunity. In the search for new vaccine adjuvants, the majority of most recent studies have evaluated PRR ligands [41]. Moreover, research efforts have also focused on the development of NP carrier systems in combination with immunostimulatory molecules to induce a synergistic response and drive cell-mediated immune responses. Numerous studies have shown successful delivery of TLR agonists using NPs $[42,43]$.

\section{THE SKIN: A POTENTIAL SOLUTION}

In order to increase the immunogenicity of vaccines and advance in vaccine delivery research, recent efforts have evaluated alternative methods for needle-free vaccine delivery. These have included oral [44], nasal [45], sublingual [46] and dermal delivery [47]. Alternative methods must prove to be equal or superior to the current ones, from an immunogenic perspective. In this regard, the rapid progression in the understanding of DC biology has prompted researchers to develop vaccine delivery strategies that target these professional APCs [7]. The skin, a highly competent immunologic organ, is densely populated with DCs and, for this reason, in addition to its ease of access, has garnered substantial interest as a route for vaccination. However, delivery of vaccines via this route is also not without its challenges. Intradermal injection necessitates healthcare providers with specialised training, often results in 
inconsistent delivery and does not reliably target the skin. Moreover, topical application of vaccine formulations to the skin does not typically generate an adequate immune response [48]. The skin, by virtue of its function for protection against the external environment, has traditionally been seen as a barrier through which vaccines could not be delivered. To fully appreciate the hurdles which have had to be conquered to successfully deliver vaccines via his route, it is important to understand the skin architecture and structure. Accordingly, a brief digression on this topic is provided.

\subsection{Fundamental aspects of skin architecture and structure}

The skin is the most complex and largest organ of the human body, forming a barrier that limits the loss of water and other components from the body and acts as a shield protecting internal organs from physical, chemical and microbial insults. Additionally, the skin has pivotal immune and sensory functions and is involved in the regulation of body temperature. Structurally the mammalian skin is composed of three distinct layers, namely, the epidermis, dermis and subcutaneous fat layer (subcutis) [49].

The outermost layer of the skin, the epidermis, is formed by the viable epidermis and the nonviable stratum corneum (SC). It is now well-accepted and documented, that the $S C$ is responsible for the skin's defensive functions and constitutes the principal barrier to penetration of topically applied drugs. It typically has a thickness of 10-20 $\mu \mathrm{m}$, but this varies depending on a number of factors including the degree of hydration and the thickness of the skin [49]. The SC is composed of 10-25 rows of dead keratinocytes (corneocytes) embedded in the secreted lipids from lamellar bodies. The "bricks and mortar" model is a common representation of this layer. Corneocytes are polygonal, elongated and flat, thus resemble 'bricks'. On the other hand, the lipid layers that reside between the corneocytes are referred to as the 'mortar'. These 
multiple lipid bilayers are thought to be responsible for the barrier properties of the SC. They prevent desiccation of the underlying tissues by inhibiting water loss and limit the penetration of substances from the external environment. Both constituents of the SC are produced by keratinocytes at the viable epidermis. Upon migration to the skin's surface, keratinocytes release the lipid 'mortar' into the intercellular space while being transformed into corneocytes ('bricks'). Final differentiation occurs once they have reached the SC [50].

Residing below the viable epidermis is the dermis, which has a thickness of 3-4 mm and lies atop the subcutaneous fat layer. It is composed of fibroblasts and collagen that provides structural support, as well as elastin, which is responsible for the elastic properties of the skin. Each of these fibres are embedded in a mucopolysaccharide matrix. Oxygen and nutrients are supplied to the skin via the cutaneous blood supply, which also facilitates waste removal. The dermis acts as a structural support for the overlying epidermis and the embedded structures, including the nerves, blood vessels and hair follicles. The skin also contains a subcutaneous fat layer composed of fat cells linked by collagen fibres that lies between the overlying dermis and the underlying body constituents. It acts as a heat insulator and supplies nutritional support as well vascularizing and innervating the skin [50].

\subsection{Role of the skin in vaccination: an immunological perspective}

As previously highlighted, the majority of vaccines are currently delivered via injection and are deposited into the subcutaneous fat or into the muscle beneath the skin. A small number of vaccines are administered into the dermis, and fewer are applied topically onto the skin, often referred to as transcutaneous or epicutaneous vaccination [51]. Each of these routes of administration relies on the presence of DCs that reside in the tissue and readily capture antigen, process it and present it to $\mathrm{T}$ lymphocytes in the draining lymphoid organs. In contrast to 
subcutaneous fat and muscle tissue, which contain relatively few DCs, the dermis and epidermis contain a dense network of different DC subsets that are circumvented by the hypodermic needle. A more attractive and rational approach is to utilise the unique immunological properties of skin and directly target vaccines to skin DCs, thereby improving immunogenicity. The main immunological cells found within the skin are Langerhans cells (LCs) in the epidermis and the dermal DCs in the dermis. Additional cells in the skin including keratinocytes also produce cytokines, chemokines and antimicrobial peptides, which play an important role in innate immunity in the skin. Research into this approach has only more recently been investigated, and a number of studies have shown this route to be superior to that of the classical route of vaccination [5,7,52]. Antigen trafficking experiments have demonstrated that antigen delivery through the skin results in more efficient antigen migration into LN in comparison to that of conventional intramuscular delivery [53].

The SC barrier of the skin makes it difficult for antigenic compounds (usually biomolecules with a high molecular weight $>500 \mathrm{Da}$ ) to penetrate to the epidermis and dermis, in which the immune cells are located. Numerous studies have demonstrated that topical application of antigen formulations is insufficient to yield adequate immune responses. As such, physical and chemical techniques to disrupt the SC barrier have been proposed to enhance antigen delivery through the epidermis for targeting of APCs. The most common physical techniques include tape-stripping, gene guns, iontophoresis, sonophoresis, electroporation and MN [2,54-56], while chemical permeation enhancers such as alcohols, sulphoxides, essential oils, fatty acids and urea, among others, have also been studied in this field [57,58]. While iontophoresis has the advantage of acting more on the drug than on the skin, and consequently lower risk of damages to the skin structure, its use is limited to charged low molecular weight molecules. In the case of sonophoresis, despite being quite flexible and adjustable to specific needs, the process itself is complicated and carries a risk of skin burning by the ultrasound waves [2,58]. 
Given the versatility of the MN approach and the larger amount of published studies focussing on the use of this platform for transdermal vaccination, in this review we focus specifically on the use of MN to facilitate vaccine delivery.

\section{MICRONEEDLE ARRAYS CIRCUMVENT SKIN BARRIER FUNCTIONS AND FACILITATE VACCINE DELIVERY}

The first MN were conceptualised in 1976. However, only during the last 20 years have they been actively developed. MN arrays consist of a multiplicity of micro-projections arranged on a base support and can range in height from 25-2000 $\mu \mathrm{m}$ [59]. When applied to the skin surface, MNs mechanically puncture the $S C$, creating microscopic holes that permit the diffusion of a diverse range of micro and macromolecules to the dermal microcirculation. The unique characteristic of MNs is that they do not cause any pain on application [60]. They are typically fabricated such that they are long enough to penetrate the dermis, yet short and narrow enough to avoid stimulation of dermal nerves. Substantial research has been conducted in the field of MN technology utilising different materials, MN designs and fabrication methods. MNs may be fabricated from various materials including metal, silicon, carbohydrates, or FDA-approved biocompatible polymers and their mode of action is dependent upon the fabrication method [61]. In general, these materials should be biocompatible, have low toxicity, sufficient strength/toughness and be cost-effective [62]. MNs differ in their design as well as their composition (Figure 2). 
A

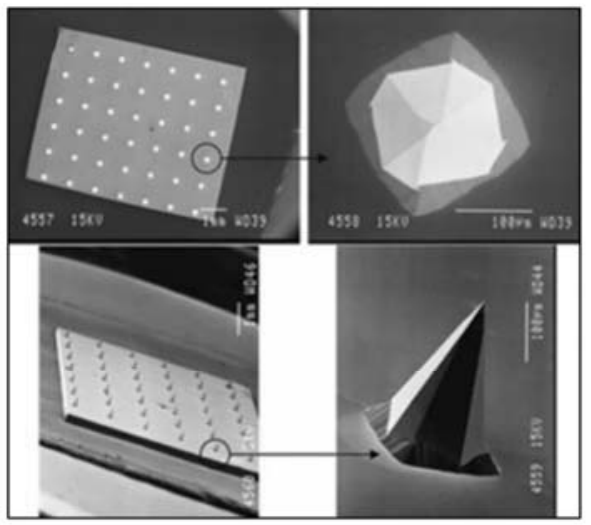

C

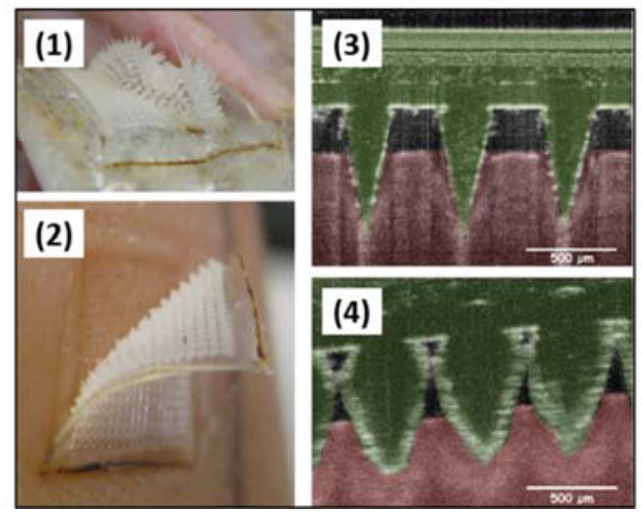

B

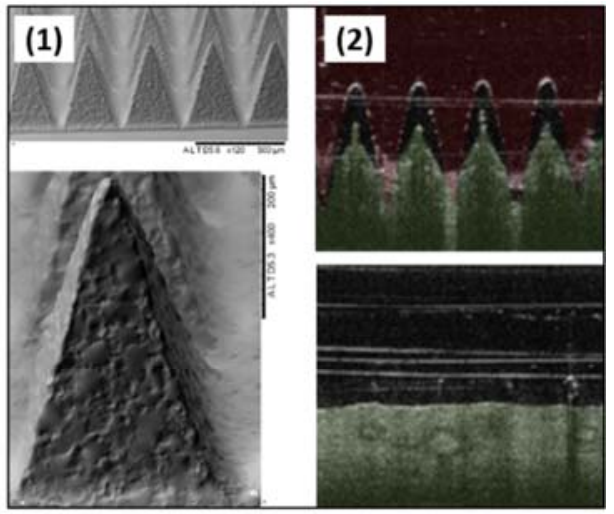

D

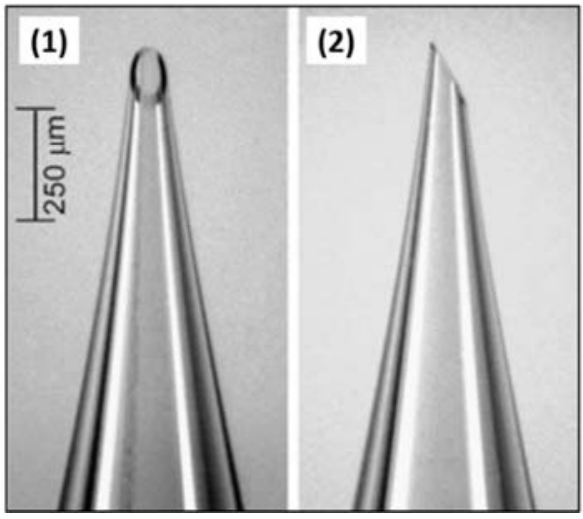

Figure 2. Representative images of different MN types. (A) SEM images of solid MN fabricated from silicon, (B) SEM images of dissolving MN fabricated from aqueous blends of Gantrez $^{\circledR}$ S97 (1) and representative OCT images of dissolving MN showing in vitro dissolution kinetics at time 0 and after $1 \mathrm{~h}$ insertion in neonatal porcine skin (2). (C) Light microscope images of a hydrogel $\mathrm{MN}$ following removal from the back of a rat (1) and the forearm of a human volunteer (2), both after $1 \mathrm{~h}$ insertion. OCT images of $\mathrm{MN}$ inserted in the forearm of a human volunteer at $\mathrm{t}=0 \mathrm{~h}$ (3) and after $1 \mathrm{~h}$ (4). (D) Front (1) and side views (2) of a representative hollow MN fabricated from glass. Reproduced with permission from [61-63], B (1) - unpublished data.

Solid MNs are most often used in a two-step procedure, whereby the MN patch is firstly applied to the skin surface, temporarily disrupting its natural permeability barrier, prior to the 
application of either a patch or topical formulation. The active molecules are then transported through the micro-conduits created by the MNs by passive diffusion. Solid MNs can be fabricated from different materials including silicon [66], biodegradable polymers such as PLGA, poly(glycolic acid) (PGA) and PLA, and metals such as stainless steel [67]. Solid MNs have been investigated for enhanced transdermal permeation of various molecules including siRNA [68], insulin [69] and vaccines [70].

Solid MN may also be used as a vehicle to carry and deposit drugs or vaccines within the skin (drug coated MNs), in this case they are referred to as coated MNs. This is carried out by coating the surface of solid MNs with a formulation containing the active agent. Upon insertion of the MNs into the skin, the coated formulation is deposited, delivering the active agent into the tissue. Solid MNs have been coated using different methods such as dipping and spraying. Coated MNs have been investigated for the delivery of vitamins [71], vaccines [72] and DNA [73]. The major disadvantage of coated MNs is that the quantity of drug or vaccine delivered is limited to the amount that that be coated onto the surface of the MNs [74].

Hollow MNs function in a manner similar to that of the conventional hypodermic needle. Once inserted into the skin they provide a defined conduit through which a liquid medication can pass through. Soluvia ${ }^{\mathrm{TM}}$ and Microjet ${ }^{\mathrm{TM}}$ are examples of hollow MNs currently on the market. Hollow MNs have been produced using different fabrication methods as reviewed by Kim et al. and have been fabricated from materials such as glass, polymers and silicon [74]. Hollow MN have been utilised for delivery of influenza vaccine. Human trials with hollow MN for influenza vaccination have demonstrated a dose-sparing effect in comparison to intramuscular vaccination [75].

Dissolving MNs are fabricated from a soluble/biodegradable material in which the active agent is embedded. Once inserted into the skin, the needles begin to dissolve and delivery of the 
active agents occurs concurrently with needle dissolution. Dissolving MN are typically produced using micromoulding techniques [59] and can be made from materials such as sugars, carbohydrates or synthetic polymers $[76,77]$. These $\mathrm{MN}$ offer the simplicity and effectiveness of other MN platforms, but eliminate the generation of biohazardous sharps waste given their dissolution upon insertion in the skin [78]. They have been used for the delivery of vaccine antigens [5,7] and insulin [79].

Finally, hydrogel-forming MNs, have been more recently developed [80]. Upon insertion into the skin they assimilate interstitial fluid and allow diffusion of the active agent from the backing through the swollen microprojections into the skin [61]. Hydrogel-forming MNs are prepared using synthetic polymers that can be easily cross-linked by chemical or physical methods. A study by Garland et al demonstrated that drug delivery from hydrogel-forming formulations can be tailored via modulation of the crosslink density of the hydrogel matrix [81]. They have been investigated for the delivery of a range of molecules of both high and low molecular weight [82]. An important property of hydrogel MN is that unlike dissolving MN, they leave no measurable polymer residue behind in the skin but are softened enough to preclude reinsertion. To date, there have been no published studies using hydrogel-forming MNs for vaccination purposes.

\subsection{MN for vaccination: development and recent applications}

Soluvia $^{\circledR}$, the world's first MN-based vaccine device was marketed in 2009 and is composed of a hollow $1.5 \mathrm{~mm}$ silicon MN which can be attached to a typical barrel syringe. It has been marketed in conjunction with an intradermal vaccine, Fluzone Intradermal ${ }^{\circledR}$, IDFlu ${ }^{\circledR}$ and Intanza $^{\circledR}$. This was an achievement for MN vaccination and since then, extensive efforts have been devoted to $\mathrm{MN}$ vaccination research, with ever more complex platforms being developed. 
Dissolving MN designs show particular promise with respect to vaccination due to their selfdisabling nature, thereby prohibiting re-use. The Prausnitz group reported the first dissolving MN for vaccination purposes in 2010 [83]. Dissolving MN (600 $\mu \mathrm{m}$ in height) were fabricated from PVP and formulated to contain $3 \mu \mathrm{g}$ of lyophilised inactivated influenza virus vaccine. It was shown that a single vaccine dose with dissolving $\mathrm{MN}$ induced protective immune responses superior to those obtained following intramuscular delivery of the same dose. Dissolving MN vaccination resulted in both antibody and cellular immune responses, leading to lung viral clearance following lethal influenza challenge. Shortly after this initial study, Kendal et al introduced a method for fabrication of multi-layered dissolving MN from master templates of their Nanopatch ${ }^{\mathrm{TM}}$ designs [84]. Carboxymethylcellulose was used for dissolving MN fabrication by casting into poly(dimethylsiloxane) moulds. The successful delivery of Quil-A adjuvanted OVA, and Fluvax ${ }^{\circledR} 2008$, a commercial influenza vaccine, was demonstrated. Results showed more efficient antibody production using dissolving MN, than those generated using the standard needle and syringe.

Following the initial studies by Prausnitz and Kendall, showing proof of concept for the use of dissolving $\mathrm{MN}$ for vaccination, numerous reports have demonstrated the delivery of various antigens using dissolving MN. OVA, due to its excellent immunogenicity and low cost, has been extensively used as a model antigen in MN studies [7,85]. Besides these studies, other experimental antigens have been delivered in numerous animal models [86,87]. In general, these studies evidenced the promising potential of this approach, with highly efficient immune responses elicited following $\mathrm{MN}$-based vaccination.

In terms of clinical development, dissolving $\mathrm{MN}$ are a relatively new vaccine delivery platform and there are limited publications from clinical studies. Two phase 1 (safety) studies have been conducted in dissolving MN containing no antigen. Prausnitz and co-workers tested the 
tolerability, usability and acceptability of dissolving MN administration in human subjects [88]. Similarly, in another clinical study, Hirobe et al observed slight erythema following application of dissolving MN fabricated from sodium hyaluronate [89]. A further study by Hirobe et al investigated the clinical safety and efficacy of an influenza vaccine. Similarly, no severe local or systemic adverse events were reported [90].

Following on from the initial studies conducted by the Prausnitz group in 2010, a phase 1 trial was recently conducted to test the safety, immunogenicity and acceptability of inactivated influenza vaccine delivered by dissolving $\mathrm{MN}$ in humans, by the same group [47]. This was a randomised, partly blinded, placebo-controlled study, carried out at Emory University. The study did not report any serious adverse events. The most common vaccination site reactions were tenderness, erythema and pruritus, although this was mild and resolved within 2-3 days, following MN removal. (Figure 3). The mean geometric mean antibody titres were similar at day 28 days between the dissolving $\mathrm{MN}$ versus the intramuscular route. 

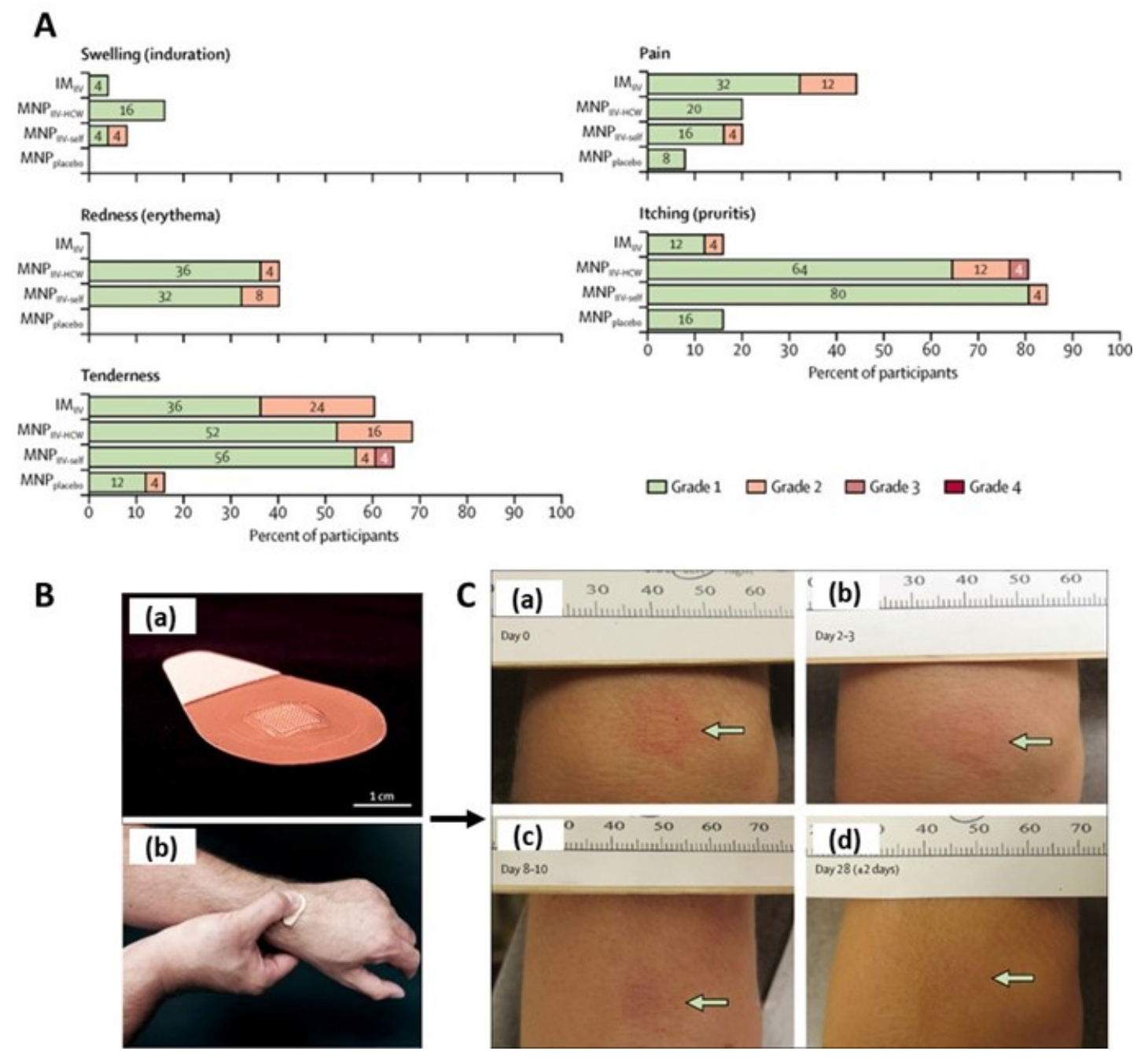

Figure 3. (A) Local responses associated with vaccination are shown. MNP - MN patch, IM intramuscular. (B) Representative image of a MN patch containing 100 needles, $650 \mu \mathrm{m}$ in height, mounted on an adhesive backing. The MN patch was manually applied to the wrist (20 min), allowing self-application by study participants. Following insertion in the skin, the needles dissolve, thus releasing vaccine in the skin layers. (C) Representative images of the typical reactions seen over time following administration and removal of $\mathrm{MN}$ patch delivery inactivated influenza vaccine. (a) day 0, (b) days 2-3, (c) days 8-10, and (d) day 28 after vaccination. Reproduced with permission from [48]. 
Despite the promising results achieved with MN-mediated vaccination approaches, it is worth mentioning the challenges associated with a potential mass production of these platforms. Large-scale manufacturing of these vaccine platforms is particularly important considering the impact that mass vaccination campaigns may have in the eradication of certain infectious diseases. In general, literature on $\mathrm{MN}$ arrays for drug and vaccine delivery describes a variety of small-scale production methods that have yet to be adapted for scale up at an industrial level $[91,92]$. Therefore, the first need in this scope is for scaled-up technologies that allow costeffective production of MN-based vaccine formulations. This may include reducing production steps, minimizing transfers between different pieces of equipment, allowing for aseptic manufacturing or final sterilization, among other strategies. Some companies are already working in this area, namely in coated and polymer-based MNs for drug delivery and cosmetic applications [93]. However, regulatory aspects including quality control assays, uniformity of content, safety of disposal and specific characteristics of packaging materials still have to be taken into consideration before a $\mathrm{MN}$ vaccine platform can be brought to the market [91].

Following on from the abovementioned studies, extensive efforts continue to be devoted to the development of various MN designs, for delivery of different antigens, with ever more complex platforms being introduced. While identifying novel adjuvant strategies, NP have gained tremendous interest, as discussed above. Moreover, researchers have more recently begun to utilise NP in combination with MP, as a two-pronged approach. Accordingly, some of the most recent advances using the combination of these two systems will now be discussed in further detail.

\section{MN-MEDIATED DELIVERY OF PARTICULATE VACCINES: A} COMBINATORIAL APPROACH FOR IMPROVED ANTIGEN DELIVERY 
NPs have been extensively studied for antigen delivery through various routes, including oral and parenteral $[94,95]$. Researchers have also attempted to use NPs for topical delivery [96]. However, to date, NP-mediated delivery to the deeper epidermis and dermis without breaching the $S C$ barrier has been met with limited success $[96,97]$. As a consequence of this, researchers investigated if the microconduits created in the skin by MNs could facilitate NP deposition into the deeper skin layers.

Zhang et al demonstrated effective delivery of fluorescent PLGA NPs $(160 \mathrm{~nm})$ into the microconduits created by MNs and permeation into the epidermis and dermis [98]. Quantitative determination showed that the percentage of applied NPs depositing in the epidermis in the MN group was greater than that of the control group (Figure 4A). The majority of the NPs were located in the epidermis. Coulman and colleagues showed diffusion of NPs through MN treated human epidermal membranes [99]. SEM images confirmed the presence of NPs to the interior surface of the microchannels following MN pre-treatment (Figure 4B). In contrast to the abovementioned studies that used MNs for pre-treatment of the skin prior to application of NPs formulation, Donnelly et al. incorporated PLGA NPs and microparticles encapsulating vitamin $\mathrm{D}_{3}\left(\mathrm{VD}_{3}\right)$ into dissolving MNs (Figure 4C) [100]. Ex-vivo deposition studies in neonatal porcine skin indicated successful delivery of $\mathrm{VD}_{3}$, which could be detected in the skin to a depth of $2.3 \mathrm{~mm}$. These studies have demonstrated the feasibility of using MNs for NPs delivery to the deeper skin layers, whether it be through MN pre-treatment of the skin, or through direct incorporation of NPs into MNs. 
A
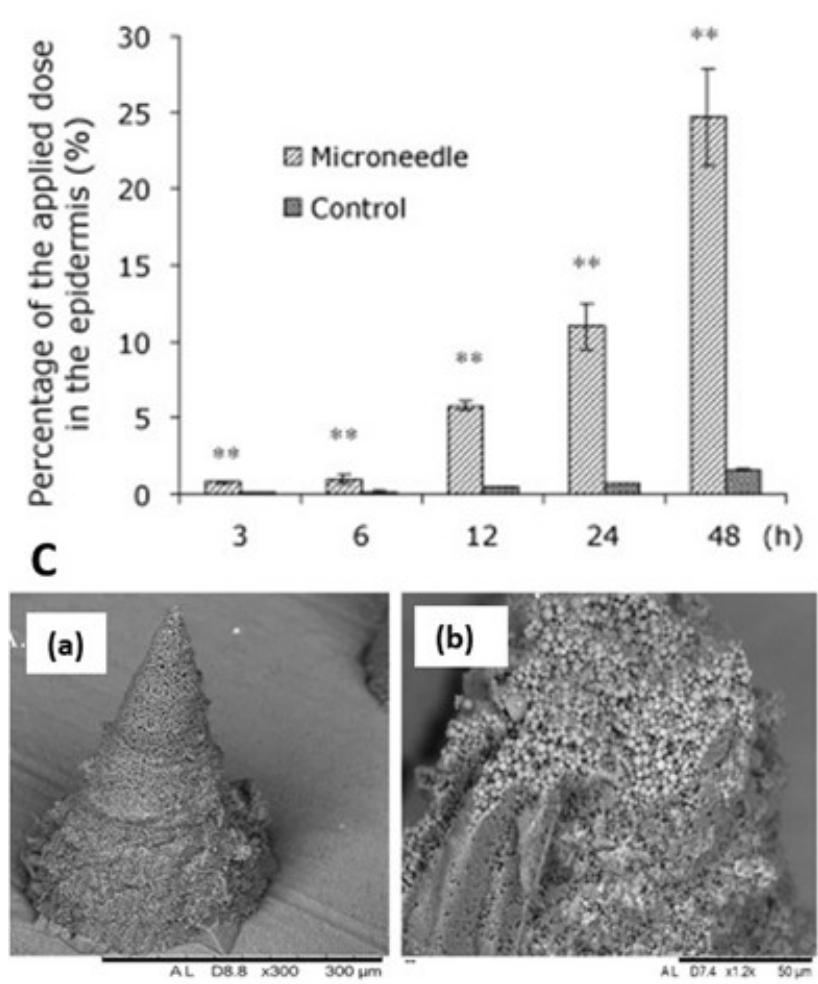

B

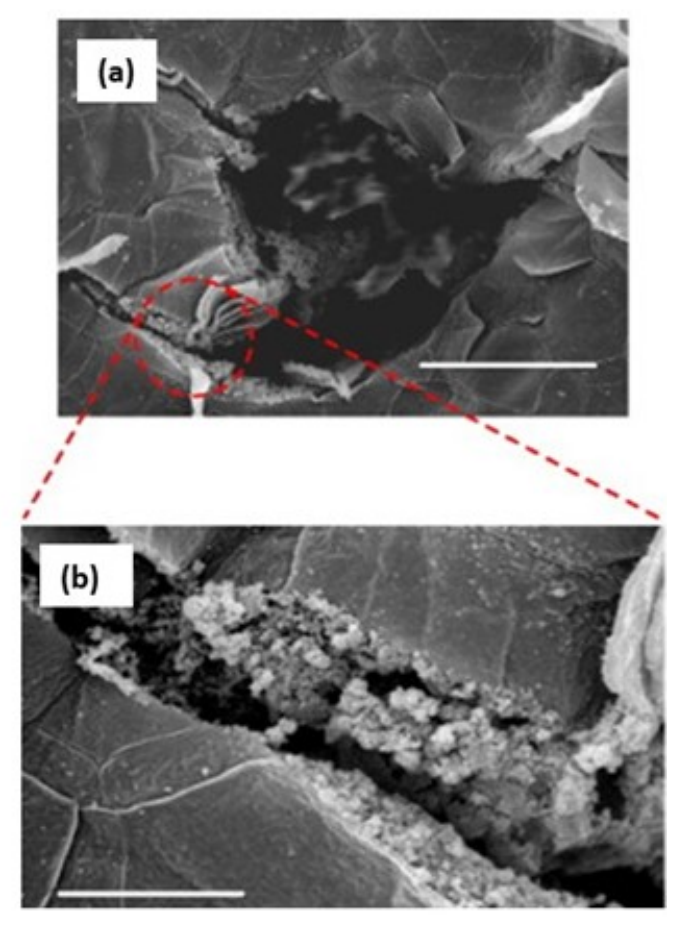

Figure 4. (A) The percentage of the applied dose of NPs $(205 \mathrm{~nm})$ deposited in the skin over a 48h period, comparing skin pre-treated with MNs and skin without MN as control. (B) SEM image of human epidermal membranes treated with MN following topical application of NP formulation (NPs: 100-150 nm). NPs could be visualised in the lateral disruptions (a) and (b), scale bar $50 \mu \mathrm{m}$. Representative images of dissolving MNs laden with PLGA NPs and microparticles (300 nm - 3.5 $\mu \mathrm{m}$ in size). Reproduced with permission from [93-95].

With reference to the use of NP formulations in combination with MNs for vaccine delivery purposes, several studies have demonstrated the feasibility of this approach. These will now be discussed in further detail in the following subsections that have been divided according to the MN modality through which the NP have been delivered. 


\subsection{Dissolving MN-mediated NP vaccination}

Zaric et al highlighted the potential of dissolving MNs for delivery of antigen encapsulated NPs for targeting of skin resident DCs [7]. OVA was used as a model antigen and encapsulated within PLGA NPs, $375 \mathrm{~nm}$ in size. It was demonstrated that fluorescent PLGA-NPs were internalised by bone-marrow-derived DCs (BMDCs) in vitro, resulting in their maturation, as assessed by up-regulation of MHCII, CD40 and CD86 molecules. Incubation of BMDMs, pulsed with empty NP (bNP) or OVA NP, with purified transgenic OT-I (CD8 $\left.{ }^{+}\right)$or OT-II $\left(\mathrm{CD}^{+}\right)$cells, demonstrated that OVA-NPs could induce antigen-specific proliferation of both $\mathrm{CD}^{+}$and $\mathrm{CD}^{+} \mathrm{OVA}$ specific $\mathrm{T}$ cells. MN-mediated vaccination in murine ears showed $\mathrm{MN}$ were capable of successfully traversing the SC barrier delivering OVA NP, resulting in the recruitment of monocytes and neutrophils to the ear skin. Following in situ uptake, skinresident DCs delivered OVA NP to cutaneous draining LN where they subsequently induced significant expansion of antigen-specific $\mathrm{T}$ cells. Finally, it was demonstrated that this approach generated robust antigen-specific cellular immune responses in mice. Complete protection was achieved in vivo against both the development of antigen-expressing B16 melanoma tumours and a murine model of para-influenza, through the activation of antigenspecific cytotoxic $\mathrm{CD}^{+} \mathrm{T}$ cells [7].

Following the initial studies by Zaric et al, a more recent study further investigated the contribution of different skin DC subsets in the induction of immune responses using $\mathrm{MN}$ mediated NP delivery [5]. Utilising skin DC ablation models, it was demonstrated that LC were the main skin DC subset capable of cross-priming antigen specific CD8+ T cells ex vivo. Moreover, it was shown that $\mathrm{LC}$ were responsible for orchestrating the differentiation of $\mathrm{CD}^{+}$

IFN $\gamma$ and IL-17 producing effectors. Depletion of LC in Lang ${ }^{\text {hDTR }}$ mice by administration of 
diphtheria toxin, had a profound effect on $\mathrm{CD} 8^{+} \mathrm{CTL}$ responses. Depletion of these cells resulted in mice exercising reduced protective anti-tumour and anti-viral immunity.

In a more recent study, Ahlam and co-workers validated a dissolving $\mathrm{MN}$ system for the delivery of a HPV DNA therapeutic vaccine. In short, the study combined a RALA peptide which condenses DNA into cationic NP, and a dissolving $\mathrm{MN}$ composed of poly(vinylpyrrolidone) (PVP) for delivery of the loaded NP. RALA condensed E6/E7 DNA into NPs, less than $100 \mathrm{~nm}$ in diameter. The E6 and E7 viral proteins disrupt tumour suppressor functions of $\mathrm{p} 53$ and the retinoblastoma protein and as such, are target antigens for therapeutic vaccination. Specifically, the E6 protein can disrupt control of cell cycle, while the E7 protein repressed regulation of the replication-associated genes. The NPs protected DNA from degradation within the PVP matrix. Vaccination of mice with MN/RALA-E6/E7 resulted in the sera of vaccinated mice having increased E6/E7-specific IgG levels. Moreover, vaccinated mice also displayed a greater T-cell mediated TC-1 cytotoxicity and higher IFN- $\gamma$ levels than those of mice which had NPs delivered intramuscularly. Finally, in a prophylactic model, it was demonstrated that MN/RALA-E6/E7 delayed TC-1 tumour initiation and in a therapeutic model, tumour growth was slowed. Importantly, MN delivery was found to be more potent than intramuscular delivery [101].

Also in the scope of therapeutic vaccines, a recent study published by Wang et al focused on the potential of $\mathrm{pH}$-degradable polymeric NPs, embedded into polymer-based MN, to deliver an antibody (aPD1) for the treatment of melanoma [102]. The authors demonstrated that hyaluronic acid-based MN arrays containing dextran-alginate NPs were able to efficiently induce tumour inhibition and increase survival in a B16F10 melanoma mice model. Moreover, this delivery was controlled by an enzymatic system of glucose oxidase and catalase coencapsulated within the nanoparticles, which produced an acidic environment in presence of 
glucose, leading to the $\mathrm{pH}$-induced degradation of the NPs. Finally, the study also showed the ability of this integrated delivery system to induce a synergic therapeutic effect when two antibodies (aPD1 and aCTLA4) were coencapsulated in the nanoparticles and delivered through the MN platform.

\subsubsection{Considerations in the manufacture of dissolving $\mathrm{MN}$ for antigen delivery}

While MN may be fabricated from a wide number of different polymers, polymer selection is typically based on in vitro characterisation experiments, such as mechanical strength and antigen compatibility. More recently, it has become evident that the material by which the MN is fabricated from, can also influence the immunological response. In fact, polymers have been used in designing new generation vaccine adjuvants. Various studies have demonstrated the adjuvant properties of different polymers including chitosan and PMVE/MA [103,104]. Of note, the $\mathrm{pH}$ of dissolving $\mathrm{MN}$ formulation may also play a role in the adjuvant properties $[105,106]$. The molecular weight of polymers has been shown to be important in terms of adjuvancy. To this end, Shakya et al observed the effect of increasing molecular weight of polymers on the adjuvant effect [107].

Polymer composition will undoubtedly influence $\mathrm{MN}$ mechanical properties and antigen delivery [59]. This, in turn, will influence the insertion properties of the $\mathrm{MN}$, causing varying damage to the skin and targeting different populations of APC, all of which will affect the immune response. For example, the transient damage to the skin following $\mathrm{MN}$ insertion can influence the immune response through the release of pro-inflammatory signals, leading to enhanced recruitment to the site of $\mathrm{MN}$ application [108]. In the case of dissolving $\mathrm{MN}$, different dissolution rates also result in different amounts of polymers and antigen being deposited in the skin, thus making direct comparison of different formulations challenging. MN application site will also influence the depth of insertion, antigen delivery and APC 
targeted. For instance, the ear is very thin, resulting in two epidermises close to each other and connected to one major draining LN. Therefore, the application of MN to this site may result in superior response to antigen than when using other sites [109]. Finally, MN parameters, such as spacing, geometry and needle density have also all been shown to influence the immunogenicity to antigens [110].

\subsection{Solid and coated MN-mediated NP vaccination}

The use of solid MN for transcutaneous immunization using antigen-loaded NP has been studied by some research groups in the last few years. The advantages, characteristics and challenges associated to this type of $\mathrm{MN}$ have also been reviewed elsewhere [93]. For instance, $4 \times 4$ arrays of metallic needles, $300 \mu \mathrm{m}$ in height, were used by Bal et al for the delivery of chitosan-based NP with either diphtheria toxoid or OVA [111,112]. In these studies, the authors compared antigen loaded in NP, to that of simple antigen-polymer mixtures and antigenpolymer conjugates. Surprisingly, NP did not result in enhanced immune responses than that induced by conjugates and physical mixtures, possibly due to the smaller size of the latter formulations in comparison with the particles. However, the authors also hypothesized that the depot effect formed by the NP at the administration site could be contributing to a lower, yet possibly longer-lasting antibody response. In all cases, results evidenced a Th2-biased immune response elicited following transcutaneous immunization with NP formulations. The observed immune responses were also generally improved upon addition of cholera toxin as an adjuvant.

Contrarily to these results, Kumar et al reported the use of solid MN, namely the Dermaroller ${ }^{\circledR}$ system, for the delivery of plasmid DNA vaccines encapsulated in PLGA NP [113]. In a preliminary study with OVA-conjugated lipid NP, the same authors compared MNs with differing heights $(200,500$ and $1000 \mu \mathrm{m})$ for their ability to efficiently deliver antigen to skin immune cells and generate an immune response [114]. Having concluded that the larger MN 
led to more efficient skin penetration of the antigen in the NPs and higher IgG levels, the authors used the $1000 \mu \mathrm{m}$ Dermaroller ${ }^{\circledR}$ system for vaccination with the developed DNA vaccine. In this case, MN-mediated administration of pDNA-loaded cationic PLGA NPs to mice induced higher IgG levels than intramuscular administration of naked DNA, and similar levels to those induced by intramuscularly administered NP. Furthermore, MN-mediated vaccination with cationic NP was the only approach capable of eliciting mucosal antibody responses, as measured by IgA levels, as well as high IL-4 and IFN- $\gamma$ levels and splenocyte proliferation.

DNA vaccines have also been explored by other research groups for MN-mediated immunization. Yin et al reported the use of star-shaped silicon MN arrays for the delivery of DNA complexes, prepared with Pluronic ${ }^{\circledR}$ and polyethyleneimine (PEI) [115]. In this case, the antigen was a Hepatitis B DNA vaccine and the complexes showed high skin penetration levels, as well as IgG levels superior to all other control groups. Correspondingly, the IFN- $\gamma$ levels observed for the group vaccinated with the complexes following MN pre-treatment were significantly higher than those achieved with all other vaccination approaches, including intramuscular administration of naked DNA. Similarly, Hu et al described positive results with a tyrosinase-related protein 2 (Trp-2) DNA vaccine, administered in polymeric NPs post MN pre-treatment [116]. Trp-2 is a melanogenic protease with overexpression in both melanocytes and melanomas, been used as a melanoma rejection antigen and shown to induce $\mathrm{CD} 8^{+} \mathrm{T}$ cells responses. The NPs, prepared with a cell-penetrating peptide, PEI and mannose residues for specific DC targeting, provided efficient in vivo antigen delivery to the skin with the combination of MN. It is worth mentioning the authors did not disclose the characteristics of the MN system used for the pre-treatment of the skin. Nevertheless, MN-mediated NP delivery resulted in high numbers of $\mathrm{CD} 11 \mathrm{c}^{+} \mathrm{DCs}$ in draining LN and spleen. Importantly, this vaccination approach resulted in Trp2-specific cellular immune responses and the subsequent 
protection of BALB/c mice against B16 melanoma challenge, with $90 \%$ survival rate achieved during the experimental period. Specifically, the NP induced $\mathrm{CD}^{+} \mathrm{T}$ cells and $\mathrm{CD} 4^{+} \mathrm{T}$ cells that produced IFN-y and IL-12 cytokines against melanoma cells, ultimately inhibiting cancer growth and improving survival time.

To date, there have only been a limited number of publications using coated $\mathrm{MN}$ for vaccination purposes, likely due to challenges surrounding the coating process and the small quantity that can be coated to the surface of the MN. As an example, Yang and co-workers used MN fabricated from PVP for delivery of Ebola vaccination using a DNA vaccine coated PLGApoly-L-lysine/poly- $\gamma$-glutamic acid (PLGA-PLL/ $\gamma$ PGA) NP. NPs, approximately $87 \mathrm{~nm}$ in size, were formulated into MNs (700 $\mu \mathrm{m}$ in height) fabricated from PVA, with a PVP/PVA backing. Mice were vaccinated four times at four-week intervals by $\mathrm{MN}$ application for $5 \mathrm{~min}$. Administration of PLGA-PLL/ $\gamma$ PGA-EboDNA via MN resulted in higher IgG1 subtype responses in comparison to that delivered intramuscularly or that induced by naked EboDNA delivered in MN or intramuscularly. No significant differences in IgG2a responses were found following vaccination with PLGA-PLL/ $\gamma$ PGA-EboDNA delivered either intramuscularly or by MN, however, naked EboDNA induced significantly weaker titres. Seok et al also developed a H1N1 DNA vaccine delivery platform using MNs coated with a polyplex containing PLGA/polyethyleneimine (PLGA/PEI) NPs [117].

\subsection{Hollow MN-mediated NP vaccination}

Hollow MNs offer the advantage of high precision in dose delivery, while circumventing the time-consuming design and formulation of coated or dissolving MN. Moreover, hollow MNs allow modification of administrative depth more readily than that of dissolving MN. However, like the conventional hypodermic needle and syringe, they have associated risks relating to 
inappropriate reuse and sharps disposal. Despite this, there use for intradermal vaccination and induction of humoral and cellular immune responses has been demonstrated.

Groot et al used hollow MNs for delivery of a model vaccine antigen loaded in PLGA NP. Anionic and cationic PLGA NP were fabricated to encapsulate the model antigen OVA, with or without the TLR3 agonist poly(I:C), as an adjuvant. An in-house developed hollow-MN applicator was used to inject the NP formulations in a precise manner into the skin. Injection of PLGA NP laden with OVA, primed both adoptively transferred antigen-specific naïve transgenic $\mathrm{CD}^{+}$and $\mathrm{CD} 4^{+} \mathrm{T}$ cells. In addition, hollow $\mathrm{MN}$-mediated vaccination with OVA PLGA NP induced priming of endogenous OVA-specific $\mathrm{CD} 8^{+} \mathrm{T}$ cells, as measured by intracellular IFN- $\gamma$ staining. The ability of this platform to induce cytotoxic $\mathrm{T}$ cell responses against an intracellular bacterium was subsequently investigated in a bacterial challenge study. Vaccinated mice were challenged with a recombinant Listeria monocytogenes secreting OVA, 21 days post vaccination, after which colony forming unit counts were determined as a measure of vaccine efficacy. In short, vaccination with soluble OVA, anionic PLGA-OVA NP and OVA in combination with poly(I:C) failed to induce protection. Protection was evident in one mouse which received cationic PLGA-OVA NP. In contrast, anionic PLGA NP co-encapsulating OVA and poly(I:C) induced full protection, resulting in all spleens being sterile.

Concurrent with the abovementioned publication, the same group conducted a comparative study of nanoparticulate vaccines for their ability to induce humoral and cellular immune responses [118]. Similarly, OVA was used as a model antigen with and without poly(I:C) as adjuvant and the aforementioned hollow MN design was used for delivery of the nanoparticulate vaccines. As shown in Figure 5 four types of NP were compared; PLGA NP, liposomes, mesoporous silica NP (MSNP) and gelatin NP (GNP) and the hollow-MN applicator delivered the particulates to a depth in murine skin of approximately $120 \mu \mathrm{m}$. 
OVA/poly(I:C) NP and OVA/ poly(I:C) solution were found to induce similar IgG and IgG1 responses. Co-encapsulation of OVA and poly(I:C) within PLGA NP significantly increased IgG2a responses when compared to that of OVA/poly(I:C) solution alone. Comparison of the different particulates showed that PLGA NP and liposomes resulted in greater IgG2a responses in comparison to that of MSNs and GNPs, likely as a consequence of the smaller NP size. In terms of cellular response, OVA/poly(I:C) liposomes induced the highest $\mathrm{CD} 8^{+}$and $\mathrm{CD} 4^{+} \mathrm{T}$ cell responses (Figure 5C and D). Together these studies demonstrate the feasibility of using hollow MN for delivery of a model protein and induction of protective humoral and cellular immune responses.

A
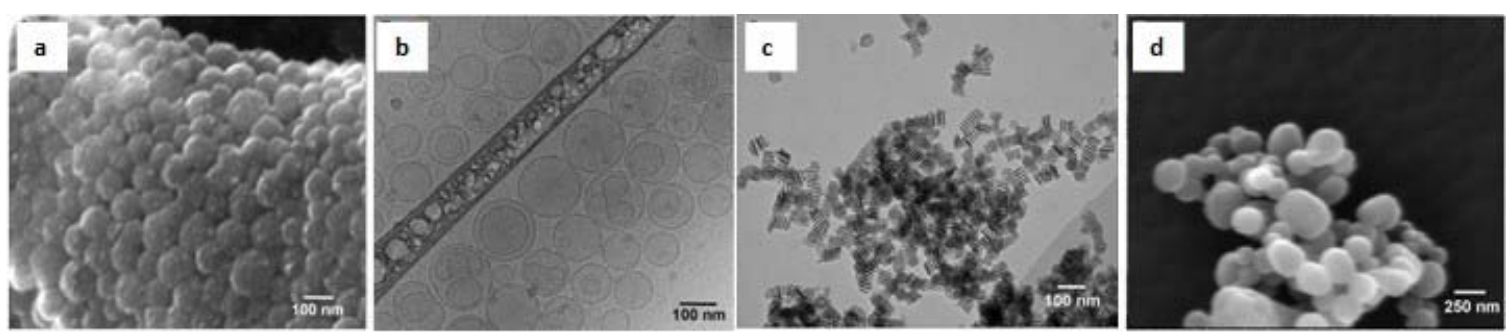

B
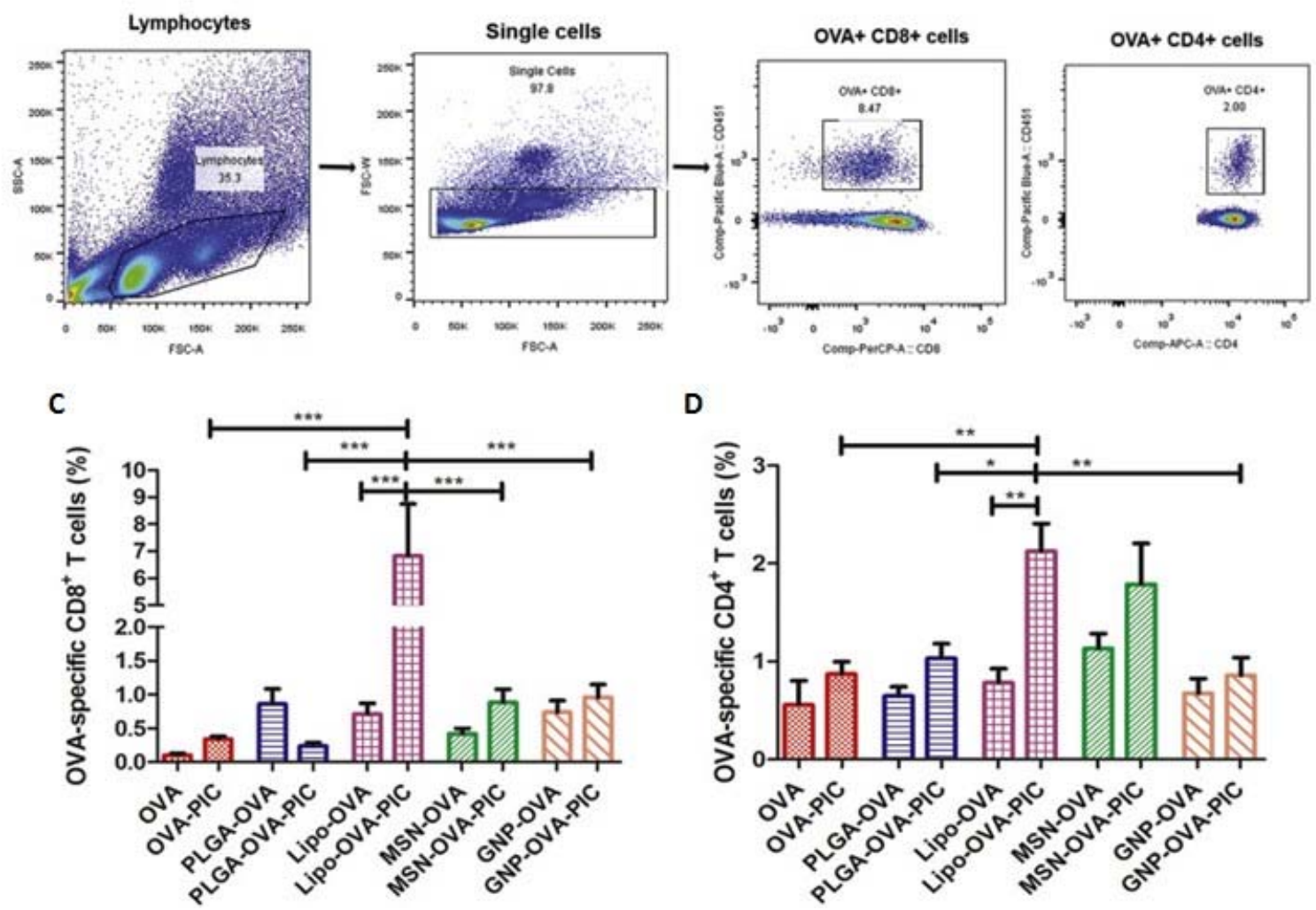
Figure 5. (A) Electron microscope images of NP. (a) Scanning electron microscopy (SEM) image of PLGA NP, (b) Cryo-EM image of liposomes, (c) transmission electron microscopy (TEM) images of MSNs, (d) SEM image of GNPs. (B) The gating strategy used to determine the $\mathrm{T}$ cell responses. Lymphocytes were gated on forward/sideward scatter, followed by the exhaustion of double or adhering cells. After pre-gating on CD4+ and CD8+ T cells, the percentage of respectively OTII and OT-I were measured by gating on CD45.1+ cells. OVA specific CD8+ (C) and CD4+ (D) responses of transferred OT-I and OT-II cells in mouse blood post immunization (7 days). Reproduced with permission from [112].

Recently, Siddhapura et al published the results of a comparison between solid and hollow MN for the delivery of antigen-loaded NP [119]. In this case, tetanus toxoid was encapsulated in chitosan-based particles and delivered through 3 hollow MN (600 $\mu \mathrm{m}$ in height) or through a roller composed of 540 solid MN with $500 \mu \mathrm{m}$ in height. Results showed controlled in vitro release of the antigen from the NP, as well as adequate in vitro cellular uptake and skin penetration. Furthermore, immunization of mice with both technologies evidenced the superior performance of hollow MN for the delivery of antigen-loaded NP. In detail, this approach led to $\mathrm{IgG}$ levels comparable to the ones achieved with intramuscular administration of a commercial vaccine and higher than the ones induced by the nanoparticles following pretreatment with solid MN. Also, hollow MN-mediated immunization led to cellular immune responses measured by the levels of IL-2, IL-4, IL-6 and IFN- $\gamma$. This work appears to corroborate the above-mentioned advantage of hollow $\mathrm{MN}$ in comparison with solid $\mathrm{MN}$, considering the amount of antigen that can be efficiently delivered to the skin. 


\section{CONCLUDING REMARKS}

The skin is densely populated with APCs, in particular DCs, and thus, is recognised as an attractive site for vaccine delivery. MNs offer an ideal platform through which these immunological cells may be targeted. Conventional methods for delivering vaccines present many logistical complications and disadvantages, which have been highlighted in this review. MNs offer the possibility of circumventing many of these obstacles, while offering the possibility for improved immune responses. Importantly, the ability to formulate vaccines in the dry state is advantageous in terms of attempting to eliminate cold chain storage. This approach is also straightforward, requiring little equipment and is cost effective. The lack of visual needles and possibility for self-application is likely to prove beneficial with regard to needle phobia and limiting the requirement for trained personnel [120]. In the case of dissolving $\mathrm{MN}$, the needles dissolve within the skin and there is no requirement for appropriate needle disposal or the fear of needle reuse, thus, prohibiting the possibility of disease transmission. From the myriad of studies that have investigated NPs for antigen delivery, it is clear that these carrier systems offer much potential. Specifically, by increasing antigen delivery and allowing for sustained release, they enhance the immune response to antigens. Clearly, the combinatorial approach of using NPs and MNs, synergistically integrates the advantages of both platforms.

\section{EXPERT OPINION}

MN-mediated vaccine delivery holds great potential for expanding access to vaccines worldwide. MN research has now reached a stage whereby commercialisation is possible. Moving forward, key considerations that require attention include formulation, manufacture and production. Manufacturing approaches will need to be considered if MN are to be mass- 
produced and industry will be required to invest significantly in appropriate equipment. Additionally, input from regulatory authorities is a pre-requisite for this technology to move forward in terms of the scale of the manufacturing process and specification for patient usage. If regulatory authorities stipulate the requirement of absolute sterility, considerations will need to be given into how this will be implemented. While the clinical safety of $\mathrm{MN}$ has been demonstrated in humans, additional studies are warranted if these technologies are to continue establishing momentum. Central to this will be an investigation into the effects of polymer deposition with the use of dissolving MN and its long-term effects. Undesirable polymer effects or toxicity issues may influence dissolving $\mathrm{MN}$ development and translation to clinical use.

Despite the abovementioned factors, it is not difficult to foresee the potential impact that MN could have. The development of novel MN-based vaccine formulations may provide a simplified approach to delivering vaccines worldwide, with patients in developing countries likely to be the main beneficiaries.

\section{ARTICLE HIGHLIGHTS}

- The invention of vaccination is one of the greatest triumphs of modern preventative medicine.

- At present, most vaccines are administered intramuscularly or subcutaneously via needle and syringe with associated disadvantages including pain, needle phobia, poor patient compliance and risk of needle-stick injuries.

- Most vaccines also require storage at specific temperatures, referred to as the cold chain, which has associated cost challenges in low resource settings. 
- $\mathrm{MN}$ arrays offer the possibility to circumvent many of the abovementioned challenges while also offering the possibility for improved vaccine immunogenicity through direct targeting of the dense network of antigen presenting cells in the skin.

- The use of nanoparticles in combination with microneedle arrays offers the possibility for enhanced vaccine immunogenicity. Specifically, by increasing antigen delivery and allowing for sustained release, they enhance the immune response to antigens.

- Key considerations that require attention include formulation, manufacture and production. Manufacturing approaches will need to be considered if $\mathrm{MN}$ are to be massproduced and industry will be required to invest significantly in appropriate equipment. 


\section{REFERENCES}

[1] Oyston P, Robinson K. The current challenges for vaccine development. J. Med. Microbiol. [Internet]. 2012;61:889-894. Available from:

http://jmm.microbiologyresearch.org/content/journal/jmm/10.1099/jmm.0.039180-0.

[2] Ita K. Transdermal delivery of vaccines - Recent progress and critical issues. Biomed. Pharmacother. [Internet]. 2016;83:1080-1088. Available from: http://linkinghub.elsevier.com/retrieve/pii/S0753332216309672.

[3] Kartoglu U, Milstien J. Tools and approaches to ensure quality of vaccines throughout the cold chain. Expert Rev. Vaccines. 2014;13:843-854.

[4] Lebre F, Hearnden CH, Lavelle EC. Modulation of Immune Responses by Particulate Materials. Adv. Mater. [Internet]. 2016;28:5525-5541. Available from: http://doi.wiley.com/10.1002/adma.201505395.

* Well-structured review on the main immune response pathways, the action of different types of particulate systems in the immune system and their potential use as vaccine adjuvants.

[5] Zaric M, Lyubomska O, Poux C, et al. Dissolving microneedle delivery of nanoparticle-encapsulated antigen elicits efficient cross-priming and th1 immune responses by murine langerhans cells. J. Invest. Dermatol. [Internet]. 2015;135:425434. Available from: http://dx.doi.org/10.1038/jid.2014.415.

[6] Marshall S, Sahm LJ, Moore AC. The success of microneedle-mediated vaccine delivery into skin. Hum. Vaccines Immunother. [Internet]. 2016;12:2975-2983. Available from: http://dx.doi.org/10.1080/21645515.2016.1171440. 
[7] Zaric M, Lyubomska O, Touzelet O, et al. Skin dendritic cell targeting via microneedle arrays laden with antigen-encapsulated poly-D, L-Lactide-Co-Glycolide nanoparticles induces efficient antitumor and antiviral immune responses. ACS Nano. 2013;7:20422055 .

[8] De Temmerman M-L, Rejman J, Demeester J, et al. Particulate vaccines: on the quest for optimal delivery and immune response. Drug Discov. Today [Internet]. 2011 [cited 2014 Aug 17];16:569-582. Available from: http://www.ncbi.nlm.nih.gov/pubmed/21570475.

[9] Woodham AW, Yan L, Skeate JG, et al. T cell ignorance is bliss: T cells are not tolerized by Langerhans cells presenting human papillomavirus antigens in the absence of costimulation. Papillomavirus Res. [Internet]. 2016;2:21-30. Available from: http://linkinghub.elsevier.com/retrieve/pii/S2405852115300069.

[10] Walsh KP, Mills KH. Dendritic cells and other innate determinants of T helper cell polarisation. Trends Immunol. [Internet]. 2013;34:521-530. Available from: http://linkinghub.elsevier.com/retrieve/pii/S1471490613001178.

[11] Chen K, McAleer JP, Lin Y, et al. Th17 Cells Mediate Clade-Specific, SerotypeIndependent Mucosal Immunity. Immunity [Internet]. 2011;35:997-1009. Available from: http://linkinghub.elsevier.com/retrieve/pii/S1074761311005140.

[12] Clem AS. Fundamentals of vaccine immunology. J. Glob. Infect. Dis. [Internet]. 2011;3:73. Available from: http://www.jgid.org/text.asp?2011/3/1/73/77299.

[13] Cohn L, Delamarre L. Dendritic cell-targeted vaccines. Front. Immunol. [Internet]. 2014 [cited 2014 Jul 10];5:255. Available from: http://www.pubmedcentral.nih.gov/articlerender.fcgi?artid=4039009\&tool=pmcentrez 
\&rendertype $=$ abstract.

[14] WHO | Injection safety policy and global campaign. WHO. 2016;

[15] Taddio A, Ipp M, Thivakaran S, et al. Survey of the prevalence of immunization noncompliance due to needle fears in children and adults. Vaccine [Internet].

2012;30:4807-4812. Available from:

http://linkinghub.elsevier.com/retrieve/pii/S0264410X1200686X.

[16] Nir Y, Paz A, Sabo E, et al. Fear of injections in young adults: Prevalence and associations. Am. J. Trop. Med. Hyg. 2003;68:341-344.

[17] Arya J, Prausnitz MR. Microneedle patches for vaccination in developing countries. J. Control. Release [Internet]. 2016;240:135-141. Available from: http://linkinghub.elsevier.com/retrieve/pii/S016836591530242X.

[18] Cordeiro AS, Alonso MJ, de la Fuente M. Nanoengineering of vaccines using natural polysaccharides. Biotechnol. Adv. [Internet]. 2015;33:1279-1293. Available from: http://dx.doi.org/10.1016/j.biotechadv.2015.05.010.

[19] Lee S, Nguyen MT. Recent Advances of Vaccine Adjuvants for Infectious Diseases. Immune Netw. [Internet]. 2015;15:51. Available from: https://synapse.koreamed.org/DOIx.php?id=10.4110/in.2015.15.2.51.

[20] Awate S, Babiuk LA, Mutwiri G. Mechanisms of Action of Adjuvants. Front. Immunol. [Internet]. 2013;4:114. Available from: http://journal.frontiersin.org/article/10.3389/fimmu.2013.00114/abstract.

[21] Di Pasquale A, Preiss S, Silva F, et al. Vaccine Adjuvants: from 1920 to 2015 and Beyond. Vaccines [Internet]. 2015;3:320-343. Available from: 
http://www.mdpi.com/2076-393X/3/2/320/.

[22] Boraschi D, Italiani P. From Antigen Delivery System to Adjuvanticy: The Board Application of Nanoparticles in Vaccinology. Vaccines [Internet]. 2015;3:930-939. Available from: http://www.mdpi.com/2076-393X/3/4/930/.

[23] Oleszycka E, Mccluskey S, Sharp FA, et al. The vaccine adjuvant alum promotes IL10 production that suppresses Th1 responses. Eur. J. Immunol. [Internet]. 2018;1-11. Available from: http://doi.wiley.com/10.1002/eji.201747150.

[24] Jacobson RM, Swan A, Adegbenro A, et al. Making vaccines more acceptable methods to prevent and minimize pain and other common adverse events associated with vaccines. Vaccine [Internet]. 2001;19:2418-2427. Available from: http://linkinghub.elsevier.com/retrieve/pii/S0264410X00004667.

[25] Elamanchili P, Lutsiak CM, Hamdy S, et al. "Pathogen-Mimicking" Nanoparticles for Vaccine Delivery to Dendritic Cells. J. Immunother. [Internet]. 2007;30:378-395. Available from: http:/content.wkhealth.com/linkback/openurl?sid=WKPTLP:landingpage\&an=000023 71-200705000-00003.

[26] Apostolopoulos V, Thalhammer T, Tzakos AG, et al. Targeting antigens to dendritic cell receptors for vaccine development. J. Drug Deliv. [Internet]. 2013;2013:869718. Available from: http://www.pubmedcentral.nih.gov/articlerender.fcgi?artid=3817681\&tool=pmcentrez \&rendertype $=$ abstract.

[27] Abd-El-Aziz AS, Abdelghani AA, El-Sadany SK, et al. Antimicrobial and anticancer activities of organoiron melamine dendrimers capped with piperazine moieties. Eur. 
Polym. J. [Internet]. 2016;82:307-323. Available from:

http://linkinghub.elsevier.com/retrieve/pii/S0014305716301938.

[28] Niikura K, Matsunaga T, Suzuki T, et al. Gold Nanoparticles as a Vaccine Platform: Influence of Size and Shape on Immunological Responses in Vitro and in Vivo. ACS Nano [Internet]. 2013;7:3926-3938. Available from: http://pubs.acs.org/doi/10.1021/nn3057005.

[29] Bibi S, Kaur R, Henriksen-Lacey M, et al. Microscopy imaging of liposomes: From coverslips to environmental SEM. Int. J. Pharm. [Internet]. 2011;417:138-150. Available from: http://linkinghub.elsevier.com/retrieve/pii/S0378517310009622.

[30] Li S, Li H, Wang X, et al. Super-Hydrophobicity of Large-Area Honeycomb-Like Aligned Carbon Nanotubes. J. Phys. Chem. B [Internet]. 2002;106:9274-9276. Available from: http://pubs.acs.org/doi/abs/10.1021/jp0209401.

[31] Gutjahr A, Phelip C, Coolen A-L, et al. Biodegradable Polymeric Nanoparticles-Based Vaccine Adjuvants for Lymph Nodes Targeting. Vaccines. 2016;4:34.

[32] Manolova V, Flace A, Bauer M, et al. Nanoparticles target distinct dendritic cell populations according to their size. Eur. J. Immunol. [Internet]. 2008;38:1404-1413. Available from: http://dx.doi.org/10.1002/eji.200737984.

** Comprehensive study of the distribution of nanoparticles with different sizes to the lymphatic system and to different populations of dendritic cells within that system, highlighting the possibility of engineering nanocarriers for more efficient antigen delivery and immune response.

[33] Petrizzo A, Conte C, Tagliamonte M, et al. Functional characterization of 
biodegradable nanoparticles as antigen delivery system. J. Exp. Clin. Cancer Res. [Internet]. 2015;34:114. Available from: http://www.jeccr.com/content/34/1/114.

[34] Joshi VB, Geary SM, Salem AK. Biodegradable particles as vaccine delivery systems: size matters. AAPS J. [Internet]. 2013;15:85-94. Available from: http://dx.doi.org/10.1208/s12248-012-9418-6.

[35] Jia J, Zhang W, Liu Q, et al. Adjuvanticity Regulation by Biodegradable Polymeric Nano/microparticle Size. Mol. Pharm. [Internet]. 2017;14:14-22. Available from: http://pubs.acs.org/doi/10.1021/acs.molpharmaceut.6b00434.

[36] Newman KD, Elamanchili P, Kwon GS, et al. Uptake of poly(D,L-lactic-co-glycolic acid) microspheres by antigen-presenting cells in vivo. J. Biomed. Mater. Res. [Internet]. 2002;60:480-486. Available from: http://doi.wiley.com/10.1002/jbm.10019.

[37] Sharma G, Valenta DT, Altman Y, et al. Polymer particle shape independently influences binding and internalization by macrophages. J. Control. Release [Internet]. 2010;147:408-412. Available from: http://linkinghub.elsevier.com/retrieve/pii/S0168365910006437.

[38] Cruz LJ, Rosalia RA, Kleinovink JW, et al. Targeting nanoparticles to CD40, DEC205 or CD11c molecules on dendritic cells for efficient CD8+ T cell response: A comparative study. J. Control. Release [Internet]. 2014;192:209-218. Available from: http://linkinghub.elsevier.com/retrieve/pii/S0168365914005215.

[39] Tamayo I, Irache JM, Mansilla C, et al. Poly(Anhydride) Nanoparticles Act as Active Th1 Adjuvants through Toll-Like Receptor Exploitation. Clin. Vaccine Immunol. [Internet]. 2010;17:1356-1362. Available from: http://cvi.asm.org/cgi/doi/10.1128/CVI.00164-10. 
[40] Sharp FA, Ruane D, Claass B, et al. Uptake of particulate vaccine adjuvants by dendritic cells activates the NALP3 inflammasome. Proc. Natl. Acad. Sci. $2009 ; 106: 870-875$.

[41] Gutjahr A, Tiraby G, Perouzel E, et al. Triggering Intracellular Receptors for Vaccine Adjuvantation. Trends Immunol. [Internet]. 2016;37:573-587. Available from: http://dx.doi.org/10.1016/j.it.2016.07.001.

[42] Margaroni M, Agallou M, Kontonikola K, et al. PLGA nanoparticles modified with a TNF $\alpha$ mimicking peptide, soluble Leishmania antigens and MPLA induce T cell priming in vitro via dendritic cell functional differentiation. Eur. J. Pharm. Biopharm. [Internet]. 2016;105:18-31. Available from: http://linkinghub.elsevier.com/retrieve/pii/S0939641116301837.

[43] Ebrahimian M, Hashemi M, Maleki M, et al. Co-delivery of Dual Toll-Like Receptor Agonists and Antigen in Poly(Lactic-Co-Glycolic) Acid/Polyethylenimine Cationic Hybrid Nanoparticles Promote Efficient In Vivo Immune Responses. Front. Immunol. [Internet]. 2017;8:1077. Available from: http://journal.frontiersin.org/article/10.3389/fimmu.2017.01077/full.

[44] Villena J, Medina M, Racedo S, et al. Resistance of Young Mice to Pneumococcal Infection can be Improved by Oral Vaccination with Recombinant Lactococcus lactis. J. Microbiol. Immunol. Infect. [Internet]. 2010;43:1-10. Available from: http://linkinghub.elsevier.com/retrieve/pii/S1684118210600011.

[45] Arulanandam B, Lynch J, Briles D, et al. Intranasal Vaccination with Pneumococcal Surface Protein A and Interleukin-12 Augments Antibody-Mediated Opsonization and Protective Immunity against Streptococcus pneumoniae Infection. Infect. Immun. 
[Internet]. 2001;69:6718-6724. Available from:

http://iai.asm.org/cgi/doi/10.1128/IAI.69.11.6718-6724.2001.

[46] Song J-H, Nguyen HH, Cuburu N, et al. Sublingual vaccination with influenza virus protects mice against lethal viral infection. Proc. Natl. Acad. Sci. [Internet]. 2008;105:1644-1649. Available from: http://www.pnas.org/cgi/doi/10.1073/pnas.0708684105.

[47] Rouphael NG, Paine M, Mosley R, et al. The safety, immunogenicity, and acceptability of inactivated influenza vaccine delivered by microneedle patch (TIVMNP 2015): a randomised, partly blinded, placebo-controlled, phase 1 trial. Lancet [Internet]. 2017;390:649-658. Available from: http://linkinghub.elsevier.com/retrieve/pii/S0140673617305755.

** Promising outcomes of the first phase I clinical trial on the safety, immunogenicity and acceptability of a dissolving $\mathrm{MN}$ vaccine patch by healthy adults.

[48] Mitragotri S. Immunization without needles. Nat. Rev. Immunol. [Internet]. 2005;5:905-916. Available from: http://www.nature.com/articles/nri1728.

[49] Baroli B. Penetration of nanoparticles and nanomaterials in the skin: Fiction or reality? J. Pharm. Sci. [Internet]. 2010;99:21-50. Available from: http://linkinghub.elsevier.com/retrieve/pii/S0022354916303434.

[50] Jepps OG, Dancik Y, Anissimov YG, et al. Modeling the human skin barrier Towards a better understanding of dermal absorption. Adv. Drug Deliv. Rev. [Internet]. 2013;65:152-168. Available from: http://linkinghub.elsevier.com/retrieve/pii/S0169409X12001226. 
[51] Al-Zahrani S, Zaric M, McCrudden CM, et al. Microneedle-mediated vaccine delivery: Harnessing cutaneous immunobiology to improve efficacy. Expert Opin. Drug Deliv. [Internet]. 2012;9:541-550. Available from: http://www.tandfonline.com/doi/full/10.1517/17425247.2012.676038.

[52] Romani N, Flacher V, Tripp CH, et al. Targeting Skin Dendritic Cells to Improve Intradermal Vaccination. Curr. Top. Microbiol. Immunol. [Internet]. Europe PMC Funders; 2011.p. 113-138. Available from: http://link.springer.com/10.1007/82_2010_118.

[53] Steinman RM, Banchereau J. Taking dendritic cells into medicine. Nature [Internet]. 2007;449:419-426. Available from: http://www.nature.com/articles/nature06175.

[54] Zhao Z, Ukidve A, Dasgupta A, et al. Transdermal immunomodulation: Principles, advances and perspectives. Adv. Drug Deliv. Rev. [Internet]. 2018;127:3-19. Available from: https://doi.org/10.1016/j.addr.2018.03.010.

* Good overview of the different strategies developed for transdermal immunization and immunomodulation, including advantages and disadvantages of the main approaches in this field.

[55] Godefroy S, Peyre M, Garcia N, et al. Effect of Skin Barrier Disruption on Immune Responses to Topically Applied Cross-Reacting Material, CRM197, of Diphtheria Toxin. Infect. Immun. [Internet]. 2005;73:4803-4809. Available from: http://iai.asm.org/cgi/doi/10.1128/IAI.73.8.4803-4809.2005.

[56] Weber CS, Hainz K, Deressa T, et al. Immune Reactions against Gene Gun Vaccines Are Differentially Modulated by Distinct Dendritic Cell Subsets in the Skin. Haziot A, editor. PLoS One [Internet]. 2015;10:e0128722. Available from: 
http://dx.plos.org/10.1371/journal.pone.0128722.

[57] Paudel KS, Milewski M, Swadley CL, et al. Challenges and opportunities in dermal/transdermal delivery. Ther. Deliv. [Internet]. 2010;1:109-131. Available from: http://www.future-science.com/doi/10.4155/tde.10.16.

[58] Alkilani AZ, McCrudden MT, Donnelly RF. Transdermal drug delivery: Innovative pharmaceutical developments based on disruption of the barrier properties of the stratum corneum. Pharmaceutics. 2015;7:438-470.

[59] Donnelly RF, Majithiya R, Singh TR, et al. Design, optimization and characterisation of polymeric microneedle arrays prepared by a novel laser-based micromoulding technique. Pharm. Res. [Internet]. 2011;28:41-57. Available from: http://link.springer.com/10.1007/s11095-010-0169-8.

[60] Haq MI, Smith E, John DN, et al. Clinical administration of microneedles: skin puncture, pain and sensation. Biomed. Microdevices [Internet]. 2009;11:35-47. Available from: http://link.springer.com/10.1007/s10544-008-9208-1.

[61] Quinn HL, Kearney M-C, Courtenay AJ, et al. The role of microneedles for drug and vaccine delivery. Expert Opin. Drug Deliv. [Internet]. 2014;11:1769-1780. Available from: http://www.tandfonline.com/doi/full/10.1517/17425247.2014.938635.

[62] Leone M, Mönkäre J, Bouwstra JA, et al. Dissolving Microneedle Patches for Dermal Vaccination. Pharm. Res. [Internet]. 2017;34:2223-2240. Available from: http://link.springer.com/10.1007/s11095-017-2223-2.

[63] González-Vázquez P, Larrañeta E, McCrudden MT, et al. Transdermal delivery of gentamicin using dissolving microneedle arrays for potential treatment of neonatal 
sepsis. J. Control. Release [Internet]. 2017;265:30-40. Available from: http://dx.doi.org/10.1016/j.jconrel.2017.07.032.

[64] Caffarel-Salvador E, Brady AJ, Eltayib E, et al. Hydrogel-Forming Microneedle Arrays Allow Detection of Drugs and Glucose In Vivo: Potential for Use in Diagnosis and Therapeutic Drug Monitoring. Chan C, editor. PLoS One [Internet]. 2015;10:e0145644. Available from: http://dx.plos.org/10.1371/journal.pone.0145644.

[65] Larrañeta E, Lutton RE, Woolfson AD, et al. Microneedle arrays as transdermal and intradermal drug delivery systems: Materials science, manufacture and commercial development. Mater. Sci. Eng. R Reports [Internet]. 2016;104:1-32. Available from: http://linkinghub.elsevier.com/retrieve/pii/S0927796X16300213.

[66] Wei-Ze L, Mei-Rong H, Jian-Ping Z, et al. Super-short solid silicon microneedles for transdermal drug delivery applications. Int. J. Pharm. [Internet]. 2010;389:122-129. Available from: http://linkinghub.elsevier.com/retrieve/pii/S0378517310000578.

[67] Martanto W, Davis SP, Holiday NR, et al. Transdermal Delivery of Insulin Using Microneedles in Vivo. Pharm. Res. [Internet]. 2004;21:947-952. Available from: http://link.springer.com/10.1023/B:PHAM.0000029282.44140.2e.

[68] Deng Y, Chen J, Zhao Y, et al. Transdermal Delivery of siRNA through Microneedle Array. Sci. Rep. [Internet]. 2016;6:21422. Available from: http://www.nature.com/articles/srep21422.

[69] McAllister D V, Wang PM, Davis SP, et al. Microfabricated needles for transdermal delivery of macromolecules and nanoparticles: Fabrication methods and transport studies. Proc. Natl. Acad. Sci. [Internet]. 2003;100:13755-13760. Available from: http://www.pnas.org/cgi/doi/10.1073/pnas.2331316100. 
[70] Ding Z, Van Riet E, Romeijn S, et al. Immune Modulation by Adjuvants Combined with Diphtheria Toxoid Administered Topically in BALB/c Mice After Microneedle Array Pretreatment. Pharm. Res. [Internet]. 2009;26:1635-1643. Available from: http://link.springer.com/10.1007/s11095-009-9874-6.

[71] Gill HS, Prausnitz MR. Coated microneedles for transdermal delivery. J. Control. Release [Internet]. 2007;117:227-237. Available from: http://linkinghub.elsevier.com/retrieve/pii/S0168365906005839.

[72] Kim Y-C, Quan F-S, Compans RW, et al. Formulation and coating of microneedles with inactivated influenza virus to improve vaccine stability and immunogenicity. $\mathrm{J}$. Control. Release [Internet]. 2010;142:187-195. Available from: http://linkinghub.elsevier.com/retrieve/pii/S0168365909007081.

[73] Gill H, Söderholm J, Prausnitz MR, et al. Cutaneous vaccination using microneedles coated with hepatitis C DNA vaccine. Gene Ther. [Internet]. 2010;17:811-814. Available from: http://www.nature.com/articles/gt201022.

[74] Kim Y-C, Park J-H, Prausnitz MR. Microneedles for drug and vaccine delivery. Adv. Drug Deliv. Rev. [Internet]. 2012;64:1547-1568. Available from: http://linkinghub.elsevier.com/retrieve/pii/S0169409X12001251.

[75] Van Damme P, Oosterhuis-Kafeja F, Van der Wielen M, et al. Safety and efficacy of a novel microneedle device for dose sparing intradermal influenza vaccination in healthy adults. Vaccine [Internet]. 2009;27:454-459. Available from: http://linkinghub.elsevier.com/retrieve/pii/S0264410X08014515.

* Interesting results on a prospective efficacy and safety trial in healthy humans, using hollow MN for immunization against influenza. 
[76] Tuan-Mahmood TM, McCrudden MT, Torrisi BM, et al. Microneedles for intradermal and transdermal drug delivery. Eur. J. Pharm. Sci. [Internet]. 2013;50:623-637. Available from: http://dx.doi.org/10.1016/j.ejps.2013.05.005.

[77] Donnelly RF, Singh TRR, Morrow DI, et al. Microneedle-mediated Transdermal and Intradermal Drug Delivery. John Wiley \& Sons; 2012.

[78] Kim Y-C, Prausnitz MR. Enabling skin vaccination using new delivery technologies. Drug Deliv. Transl. Res. [Internet]. 2011;1:7-12. Available from: http://link.springer.com/10.1007/s13346-010-0005-z.

[79] Ito Y, Hirono M, Fukushima K, et al. Two-layered dissolving microneedles formulated with intermediate-acting insulin. Int. J. Pharm. [Internet]. 2012;436:387-393. Available from: http://linkinghub.elsevier.com/retrieve/pii/S037851731200645X.

[80] Donnelly RF, McCrudden MT, Alkilani AZ, et al. Hydrogel-forming microneedles prepared from "super swelling" polymers combined with lyophilised wafers for transdermal drug delivery. PLoS One. 2014;9.

[81] Garland MJ, Singh TRR, Woolfson AD, et al. Electrically enhanced solute permeation across poly(ethylene glycol)-crosslinked poly(methyl vinyl ether-co-maleic acid) hydrogels: Effect of hydrogel crosslink density and ionic conductivity. Int. J. Pharm. [Internet]. 2011;406:91-98. Available from: http://linkinghub.elsevier.com/retrieve/pii/S0378517311000093.

[82] Donnelly RF, Thakur RRS, Garland MJ, et al. Hydrogel-forming microneedle arrays for enhanced transdermal drug delivery. Adv. Funct. Mater. 2012;22:4879-4890.

[83] Sullivan SP, Koutsonanos DG, del Pilar Martin M, et al. Dissolving polymer 
microneedle patches for influenza vaccination. Nat. Med. [Internet]. 2010;16:915-920. Available from: http://www.nature.com/articles/nm.2182.

[84] Raphael AP, Prow TW, Crichton ML, et al. Targeted, Needle-Free Vaccinations in Skin using Multilayered, Densely-Packed Dissolving Microprojection Arrays. Small [Internet]. 2010;6:1785-1793. Available from: http://doi.wiley.com/10.1002/smll.201000326.

[85] McCrudden MT, Torrisi BM, Al-Zahrani S, et al. Laser-engineered dissolving microneedle arrays for protein delivery: Potential for enhanced intradermal vaccination. J. Pharm. Pharmacol. 2015;67:409-425.

[86] Hsueh K-J, Chen M-C, Cheng L-T, et al. Transcutaneous immunization of Streptococcus suis bacterin using dissolving microneedles. Comp. Immunol. Microbiol. Infect. Dis. [Internet]. 2017;50:78-87. Available from: http://linkinghub.elsevier.com/retrieve/pii/S0147957116301229.

[87] Esser ES, Romanyuk A, Vassilieva E V, et al. Tetanus vaccination with a dissolving microneedle patch confers protective immune responses in pregnancy. J. Control. Release [Internet]. 2016;236:47-56. Available from: http://linkinghub.elsevier.com/retrieve/pii/S0168365916303935.

[88] Arya J, Henry S, Kalluri H, et al. Tolerability, usability and acceptability of dissolving microneedle patch administration in human subjects. Biomaterials [Internet]. 2017;128:1-7. Available from: http://linkinghub.elsevier.com/retrieve/pii/S014296121730128X

[89] Hirobe S, Azukizawa H, Matsuo K, et al. Development and Clinical Study of a SelfDissolving Microneedle Patch for Transcutaneous Immunization Device. Pharm. Res. 
[Internet]. 2013;30:2664-2674. Available from:

http://link.springer.com/10.1007/s11095-013-1092-6.

[90] Hirobe S, Azukizawa H, Hanafusa T, et al. Clinical study and stability assessment of a novel transcutaneous influenza vaccination using a dissolving microneedle patch. Biomaterials [Internet]. 2015;57:50-58. Available from: http://linkinghub.elsevier.com/retrieve/pii/S0142961215003543.

[91] Donnelly RF, Woolfson AD. Patient safety and beyond: what should we expect from microneedle arrays in the transdermal delivery arena? Ther. Deliv. 2014;5:653-662.

[92] Donnelly RF. How can microneedles overcome challenges facing transdermal drug delivery? Ther. Deliv. 2017;8:725-728.

[93] Prausnitz MR. Engineering Microneedle Patches for Vaccination and Drug Delivery to Skin. Annu. Rev. Chem. Biomol. Eng. [Internet]. 2017;8:9.1-9.24. Available from: http://www.annualreviews.org/doi/10.1146/annurev-chembioeng-060816-101514.

** Comprehensive review of the different aims, characteristics, manufacturing, use and outcomes for solid MN patches.

[94] Sarti F, Perera G, Hintzen F, et al. In vivo evidence of oral vaccination with PLGA nanoparticles containing the immunostimulant monophosphoryl lipid A. Biomaterials [Internet]. 2011;32:4052-4057. Available from: http://linkinghub.elsevier.com/retrieve/pii/S0142961211001633.

[95] Rauta PR, Nayak B. Parenteral immunization of PLA/PLGA nanoparticle encapsulating outer membrane protein (Omp) from Aeromonas hydrophila: Evaluation of immunostimulatory action in Labeo rohita (rohu). Fish Shellfish Immunol. 
[Internet]. 2015;44:287-294. Available from:

http://linkinghub.elsevier.com/retrieve/pii/S1050464815000601.

[96] Alvarez-Román R, Naik A, Kalia Y, et al. Skin penetration and distribution of polymeric nanoparticles. J. Control. Release [Internet]. 2004;99:53-62. Available from: http://linkinghub.elsevier.com/retrieve/pii/S0168365904002858.

[97] Schneider M, Stracke F, Hansen S, et al. Nanoparticles and their interactions with the dermal barrier. Dermatoendocrinol. 2009;1:197-206.

[98] Zhang W, Gao J, Zhu Q, et al. Penetration and distribution of PLGA nanoparticles in the human skin treated with microneedles. Int. J. Pharm. [Internet]. 2010;402:205-212. Available from: http://linkinghub.elsevier.com/retrieve/pii/S037851731000757X.

[99] Coulman SA, Anstey A, Gateley C, et al. Microneedle mediated delivery of nanoparticles into human skin. Int. J. Pharm. [Internet]. 2009;366:190-200. Available from: http://linkinghub.elsevier.com/retrieve/pii/S0378517308006054.

[100] Vora LK, Donnelly RF, Larrañeta E, et al. Novel bilayer dissolving microneedle arrays with concentrated PLGA nano-microparticles for targeted intradermal delivery: Proof of concept. J. Control. Release [Internet]. 2017;0-1. Available from: http://www.sciencedirect.com/science/article/pii/S0168365917308921.

[101] Ali AA, McCrudden CM, McCaffrey J, et al. DNA vaccination for cervical cancer; a novel technology platform of RALA mediated gene delivery via polymeric microneedles. Nanomedicine Nanotechnology, Biol. Med. [Internet]. 2017;13:921932. Available from: http://dx.doi.org/10.1016/j.nano.2016.11.019.

[102] Wang C, Ye Y, Hochu GM, et al. Enhanced Cancer Immunotherapy by Microneedle 
Patch-Assisted Delivery of Anti-PD1 Antibody. Nano Lett. 2016;16:2334-2340.

[103] Carroll EC, Jin L, Mori A, et al. The Vaccine Adjuvant Chitosan Promotes Cellular Immunity via DNA Sensor cGAS-STING-Dependent Induction of Type I Interferons. Immunity. 2016;44:597-608.

[104] Vandamme K, Melkebeek V, Cox E, et al. Influence of polymer hydrolysis on adjuvant effect of Gantrez ${ }^{\circledR A N}$ nanoparticles: Implications for oral vaccination. Eur. J. Pharm. Biopharm. [Internet]. 2011;79:392-398. Available from: http://linkinghub.elsevier.com/retrieve/pii/S0939641111001652.

[105] Martinez D, Vermeulen M, von Euw E, et al. Extracellular Acidosis Triggers the Maturation of Human Dendritic Cells and the Production of IL-12. J. Immunol. [Internet]. 2007;179:1950-1959. Available from: http://www.jimmunol.org/cgi/doi/10.4049/jimmunol.179.3.1950.

[106] Vermeulen M, Giordano M, Trevani AS, et al. Acidosis Improves Uptake of Antigens and MHC Class I-Restricted Presentation by Dendritic Cells. J. Immunol. [Internet]. 2004;172:3196-3204. Available from: http://www.jimmunol.org/cgi/doi/10.4049/jimmunol.172.5.3196.

[107] Shakya AK, Kumar A, Nandakumar KS. Adjuvant properties of a biocompatible thermo-responsive polymer of $\mathrm{N}$-isopropylacrylamide in autoimmunity and arthritis. J. R. Soc. Interface [Internet]. 2011;8:1748-1759. Available from: http://rsif.royalsocietypublishing.org/cgi/doi/10.1098/rsif.2011.0114.

[108] Weldon WC, Zarnitsyn VG, Esser ES, et al. Effect of Adjuvants on Responses to Skin Immunization by Microneedles Coated with Influenza Subunit Vaccine. Rodrigues MM, editor. PLoS One [Internet]. 2012;7:e41501. Available from: 
http://dx.plos.org/10.1371/journal.pone.0041501.

[109] van der Maaden K, Varypataki EM, Yu H, et al. Parameter optimization toward optimal microneedle-based dermal vaccination. Eur. J. Pharm. Sci. [Internet]. 2014;64:18-25. Available from:

http://linkinghub.elsevier.com/retrieve/pii/S0928098714003133.

[110] Depelsenaire AC, Meliga SC, McNeilly CL, et al. Colocalization of Cell Death with Antigen Deposition in Skin Enhances Vaccine Immunogenicity. J. Invest. Dermatol. [Internet]. 2014;134:2361-2370. Available from: http://linkinghub.elsevier.com/retrieve/pii/S0022202X15369876.

[111] Bal SM, Ding Z, Kersten GFA, et al. Microneedle-based transcutaneous immunisation in mice with n-trimethyl chitosan adjuvanted diphtheria toxoid formulations. Pharm. Res. 2010;27:1837-1847.

[112] Bal SM, Slütter B, Jiskoot W, et al. Small is beautiful: N-trimethyl chitosan-ovalbumin conjugates for microneedle-based transcutaneous immunisation. Vaccine [Internet]. 2011;29:4025-4032. Available from: http://dx.doi.org/10.1016/j.vaccine.2011.03.039.

[113] Kumar A, Wonganan P, Sandoval MA, et al. Microneedle-mediated transcutaneous immunization with plasmid DNA coated on cationic PLGA nanoparticles. J. Control. Release [Internet]. 2012;163:230-239. Available from: http://dx.doi.org/10.1016/j.jconrel.2012.08.011.

[114] Kumar A, Li X, Sandoval MA, et al. Permeation of antigen protein-conjugated nanoparticles and live bacteria through microneedle-treated mouse skin. Int. J. Nanomedicine. 2011;6:1253-1264. 
[115] Yin D, Liang W, Xing S, et al. Hepatitis B DNA vaccine-polycation nano-complexes enhancing immune response by percutaneous administration with microneedle. Biol. Pharm. Bull. [Internet]. 2013;36:1283-1291. Available from: http://www.ncbi.nlm.nih.gov/pubmed/23676787.

[116] $\mathrm{Hu} \mathrm{Y}, \mathrm{Xu} \mathrm{B}, \mathrm{Xu}$ J, et al. Microneedle-assisted dendritic cell-targeted nanoparticles for transcutaneous DNA immunization. Polym. Chem. [Internet]. 2015;6:373-379. Available from: http://xlink.rsc.org/?DOI=C4PY01394H.

[117] Seok H, Noh JY, Lee DY, et al. Effective humoral immune response from a H1N1 DNA vaccine delivered to the skin by microneedles coated with PLGA-based cationic nanoparticles. J. Control. Release [Internet]. 2017;265:66-74. Available from: https://doi.org/10.1016/j.jconrel.2017.04.027.

[118] Du G, Hathout RM, Nasr M, et al. Intradermal vaccination with hollow microneedles: A comparative study of various protein antigen and adjuvant encapsulated nanoparticles. J. Control. Release [Internet]. 2017;266:109-118. Available from: https://doi.org/10.1016/j.jconrel.2017.09.021.

[119] Siddhapura K, Harde H, Jain S. Immunostimulatory effect of tetanus toxoid loaded chitosan nanoparticles following microneedles assisted immunization. Nanomedicine Nanotechnology, Biol. Med. [Internet]. 2015;12:213-222. Available from: http://www.sciencedirect.com/science/article/pii/S1549963415001999.

[120] Ripolin A, Quinn J, Larrañeta E, et al. Successful application of large microneedle patches by human volunteers. Int. J. Pharm. [Internet]. 2017;521:92-101. Available from: http://linkinghub.elsevier.com/retrieve/pii/S0378517317300923. 


\section{Declaration of interest}

The authors report no conflict of interest. 